Review Article

\title{
HLA Epitopes: The Targets of Monoclonal and Alloantibodies Defined
}

\author{
Nadim El-Awar, Vadim Jucaud, and Anh Nguyen \\ Terasaki Foundation Laboratory, Los Angeles, CA, USA \\ Correspondence should be addressed to Nadim El-Awar; nelawar@terasakilab.org
}

Received 21 December 2016; Accepted 14 February 2017; Published 24 May 2017

Academic Editor: Senthami R. Selvan

Copyright @ 2017 Nadim El-Awar et al. This is an open access article distributed under the Creative Commons Attribution License, which permits unrestricted use, distribution, and reproduction in any medium, provided the original work is properly cited.

\begin{abstract}
Sensitization to human leukocyte antigens (HLA) in organ transplant patients causes graft rejection, according to the humoral theory of transplantation. Sensitization is almost ubiquitous as anti-HLA antibodies are found in almost all sera of transplant recipients. Advances in testing assays and amino acid sequencing of HLA along with computer software contributed further to the understanding of antibody-antigen reactivity. It is commonly understood that antibodies bind to HLA antigens. With current knowledge of epitopes, it is more accurate to describe that antibodies bind to their target epitopes on the surface of HLA molecular chains. Epitopes are present on a single HLA (private epitope) or shared by multiple antigens (public epitope). The phenomenon of cross-reactivity in HLA testing, often explained as cross-reactive groups (CREGs) of antigens with antibody, can be clearly explained now by public epitopes. Since 2006, we defined and reported 194 HLA class I unique epitopes, including 56 cryptic epitopes on dissociated HLA class I heavy chains, 83 HLA class II epitopes, 60 epitopes on HLA-DRB1, 15 epitopes on HLA-DQB1, 3 epitopes on HLA-DQA1, 5 epitopes on HLA-DPB1, and 7 MICA epitopes. In this paper, we provide a summary of our findings.
\end{abstract}

\section{Introduction}

Sensitization to HLA antigens in organ transplant patients causes graft rejection, according to the humoral theory of transplantation [1]. Sensitization is almost ubiquitous as it is evident in the detection of anti-HLA antibodies in the sera of recipients-in one study, almost all patients waiting for regraft of a kidney transplant have anti-HLA antibodies [2]. Determining specificity of the anti-HLA antibody has advanced in recent years using recombinant HLA single antigens (SA) coated on color-coded Luminex beads [3]. The reactivity of anti-HLA antibodies with HLA antigens and the phenomenon of cross-reactivity has been the subject of investigation for decades. Amino acid sequences of the HLA molecules which greatly contributed to our understanding of antibody and antigen reactivity has been introduced since 1963 [4-12]. Antibodies are commonly described as binding to HLA antigens; however, it is more accurate to describe the reactivity of the antibody as binding to specific epitopes on the surface of HLA antigens-epitopes are conformational amino acid arrangements and are the targets of antibodies. Some epitopes are private, found exclusively on one antigen; others are public epitopes shared by two or more antigens. The phenomenon of cross-reactivity in HLA testing, often explained as crossreactive groups (CREGs), of antigens with antibody can be clearly explained now by public epitopes-an antibody targeting a public epitope shows positive reaction with all antigens sharing the epitope.

Since 2006, we defined and reported on 194 HLA class I unique epitopes, including 138 epitopes on intact HLA class I (heavy chain $+\beta 2 \mathrm{~m}+$ peptide), and 56 cryptic epitopes on dissociated HLA class I (heavy chain only) [13-18]. 110 epitopes on intact HLA class I were defined using murine monoclonal and human alloantibodies, and the remaining 28 epitopes were defined with naturally occurring anti-HLA antibodies. Naturally occurring (natural) HLA antibodies found in cord blood and healthy males were used to define the 56 cryptic epitopes on dissociated HLA class I. In addition, 83 HLA class II unique epitopes were defined and reported, including 60 epitopes on HLA-DRB1, 15 epitopes on HLA-DQB1, 3 epitopes on HLA-DQA1, and 5 epitopes 
Main steps for epitope difinition
(1) Antibody preparation and testing with single antigen beads
Monoclonal antibody or alloantibody isolated from sera by adsorption-to then elution-from a single antigen recombinant cell line (Figure 2).

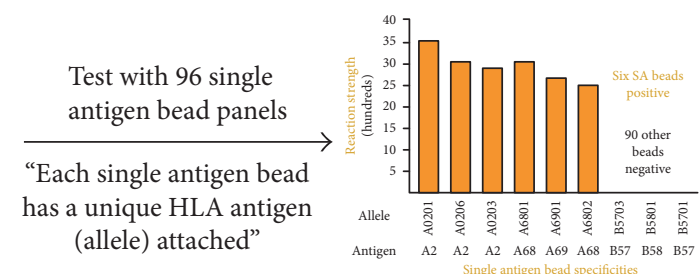

In this case, the results in the figure show that A2, 68, and 69 beads/antigen are positve while the rest ( 90 beads, not all shown) are negative-an indication that the antibody is targeting a unique epitope on the positive antigens.

(2) Exclusively unique aa's at certain positions on positive antigens

Computer software search in aa sequences of all 96 alleles shows all 6 positive alleles share the aa's $\mathbf{T}$ and $\mathbf{H}$ at positions 142 and 145 , respectively-the negative antigens/alleles (not all shown) have different aa's at these positions.

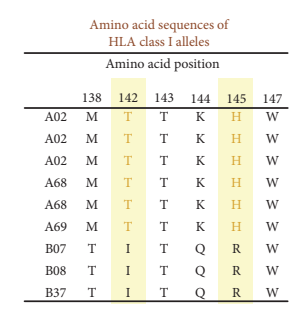

(3) Epitope definition. Use of 3D HLA aa molecular structure software to determine the following:

(i) Amino acids at the exclusicely shared positions of the positive beads are exposed to the surface of the antigens for antibody to bind.

(ii) When more than one aa defines an epitope, the distance between any two aa's is within the binding span of the antibody (Figure 3).

The empirical determination that one antibody reacts positively with some single antigens and not with others, the positive antigens that exclusively share aa's at certain sequence positions, and the exclusive aa's that are at the surface of the antigens and are within the binding span of the antibody allow for epitope definition.

Figure 1: Main empirical testing steps to define HLA epitopes.

on HLA-DPB1 [15, 19-22]. All HLA-DRB1 epitopes were defined using solely amino acid sequence data, in contrast to HLA-DQA1, HLA-DQB1, and HLA-DPB1 epitopes that were defined using human alloantibodies. Lastly, we defined and reported on 7 MICA epitopes using human alloantibodies $[15,22]$. In this paper, we provide a summary of our findings.

\section{Materials and Methods}

The principle we used to define HLA epitopes is summarized in (Figure 1). Briefly, if an antibody is determined to test positive with certain HLA antigens and negative with others, it is reasonable to assume that the antibody is targeting a specific epitope on the positive antigens. Epitopes are conformational arrangements of amino acids (aa) at sequence positions on the surface of antigens that must be within the binding span of the antibody. To define an epitope, a computer search, in published aa sequences of tested antigens, was performed to identify exclusively shared aa ane or more sequence positions among the positive antigens-these amino acids define the epitope.

Murine monoclonal antibodies or transplant recipient and healthy male HLA antibodies isolated from sera and cord blood by first adsorbing them onto appropriate recombinant HLA (rHLA) single antigen cells, then eluted with an acidic buffer (ImmunoPure IgG elution buffer, Pierce, Rockford, IL), and neutralized with $1 \mathrm{M}$ TRIS-HCl pH 9.5 (Figure 2) were all tested with the single antigen beads (One Lambda Inc., Canoga Park, CA) to determine the specificity of the antibodies [14]. HLA class I SA beads treated with a buffer that dissociates the peptide and the beta-2-microglobulin $(\beta 2 \mathrm{~m})$ from the heavy chain of the intact HLA antigens on the beads [17] were used to reveal the specificity of antibodies targeting epitopes on dissociated class I heavy chains. MFI values of 1000 or above were considered positive except when the overall reactions of an eluted antibody were weak, a cutoff of MFI 400 was used.

Computer software was utilized to search for exclusive amino acids in the structure of antigens showing positive reactions with an antibody. Searches were performed within sequences of HLA class I heavy chains, MICA antigens, DR beta chains, DQ beta and alpha chains, and DPB chains. All amino acid sequences were obtained from the HLA Informatics Group at the Anthony Nolan website [23]. One or more amino acids found exclusively at the same sequence positions in the chains of positive antigens, but not in the sequence positions of negative antigens, were designated as the defining amino acids for an epitope. The defining amino acid(s) had to be within the antibody binding span [24, 25] — estimated at $494 \AA 2-750 \AA 2$ area (Figure 3) and the aa(s) must be exposed at the surface of the antigen-exceptions are noted between parentheses (Table 1).

The efficacy of isolating HLA antibody from HLA sera with adsorption and elution assays, testing the eluted antibody with the SA beads to determine specificity and the definition of the epitope on the surface of positive antigens (corresponding to antibody specificity) are shown in (Figure 4). Alloserum with determined specificity A2, A68, A69, B57, and B58 was adsorbed separately with SA rHLA 


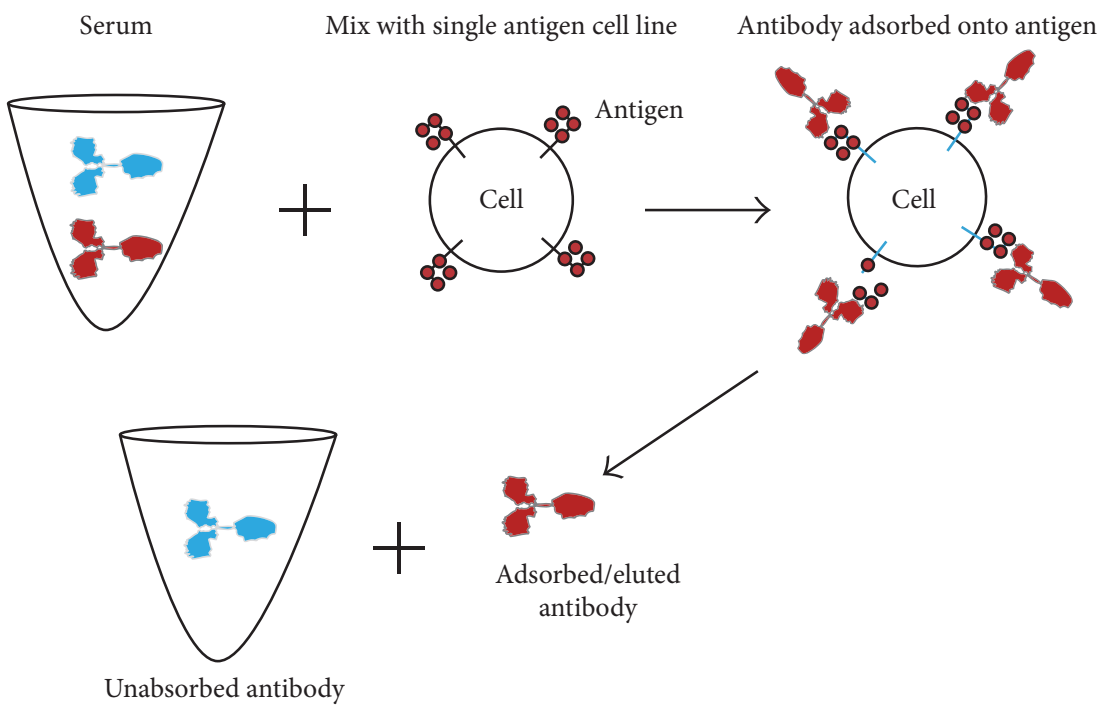

Figure 2: Alloantibody adsorption/elution with recombinant single antigen cell line. The antibody is eluted with an acidic buffer, and the eluate is neutralized with TRIS buffer.

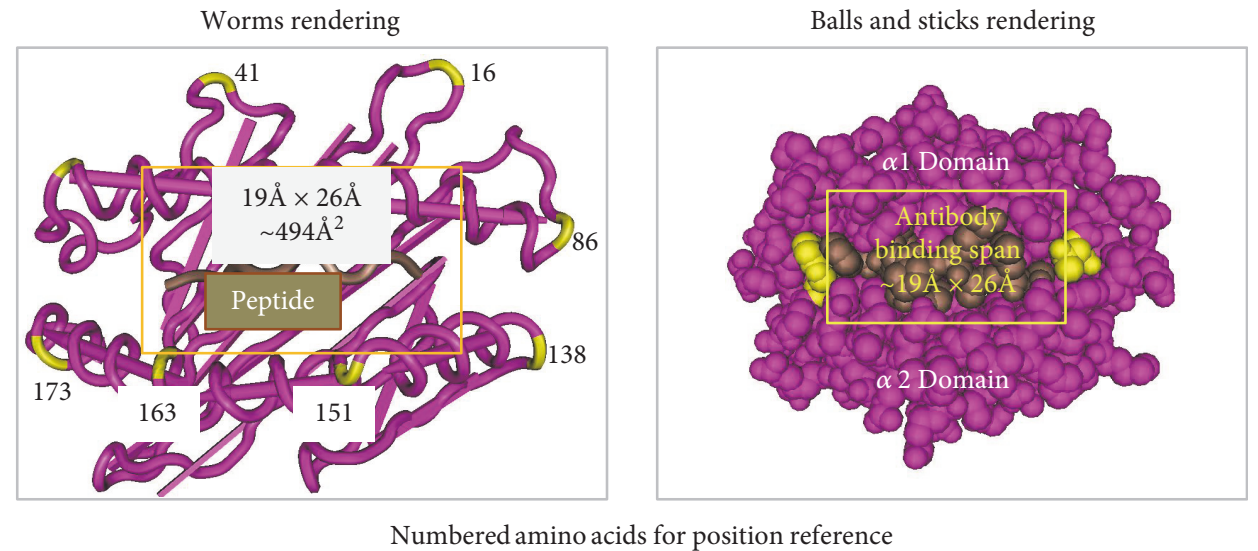

FIgURE 3: Top view of HLA class I heavy chain 1 and 2 domains. Rectangles show approximate binding span area of antibody.

A6901 and B5801 cells. Eluted antibodies tested with the SA beads showed specificity A2, A68, and A69 and A2, B57, and B58, respectively. HLA antigens A2, A68, and A69 share an epitope defined by glycine $(G)$ at position 62 ; therefore, $62 \mathrm{G}$ defines the epitope. Similarly, HLA antigens A2, B57, and $\mathrm{B} 58$ share an epitope defined by threonine (T) at position 142 or histidine $(\mathrm{H})$ at position 145 ; therefore $142 \mathrm{~T}$ or $145 \mathrm{H}$ define the epitope.

\section{Results}

3.1. Class I Epitopes on Intact Antigens. 138 unique epitopes were defined for one or a group of two or more intact HLA class I antigens. 110 unique epitopes were defined by using SA beads (Table 1, partial list; complete table in the supplemental information available online at https://doi.org/10.1155/2017/3406230) assays to test eluted alloantibodies that were adsorbed from human sera onto the surface of mammalian rHLA single antigen cells then eluted, and murine monoclonal antibodies to determine specificity of each antibody. Epitopes were defined by identifying exclusively unique amino acids among the positive antigens. Also defined were 28 unique epitopes targeted by naturally occurring anti-HLA antibodies found in sera of healthy males and in cord blood (Table 2). All epitopes were defined by identifying exclusively unique amino acids among the positive antigens. Here, we present partial lists in tables and example figures of epitopes-complete tables and other figures can be found in the supplemental information document.

The number of epitopes defined for each antigen, using human alloantibodies, varied from 4 to 23 (Table 3 ). In general, there was no correlation between the number of epitopes and the frequency of antigen in the population. For example, for HLA A2, the most frequent antigen $(f=30.3 \%$ to $54 \%)$, we defined 16 epitopes while for A25, 


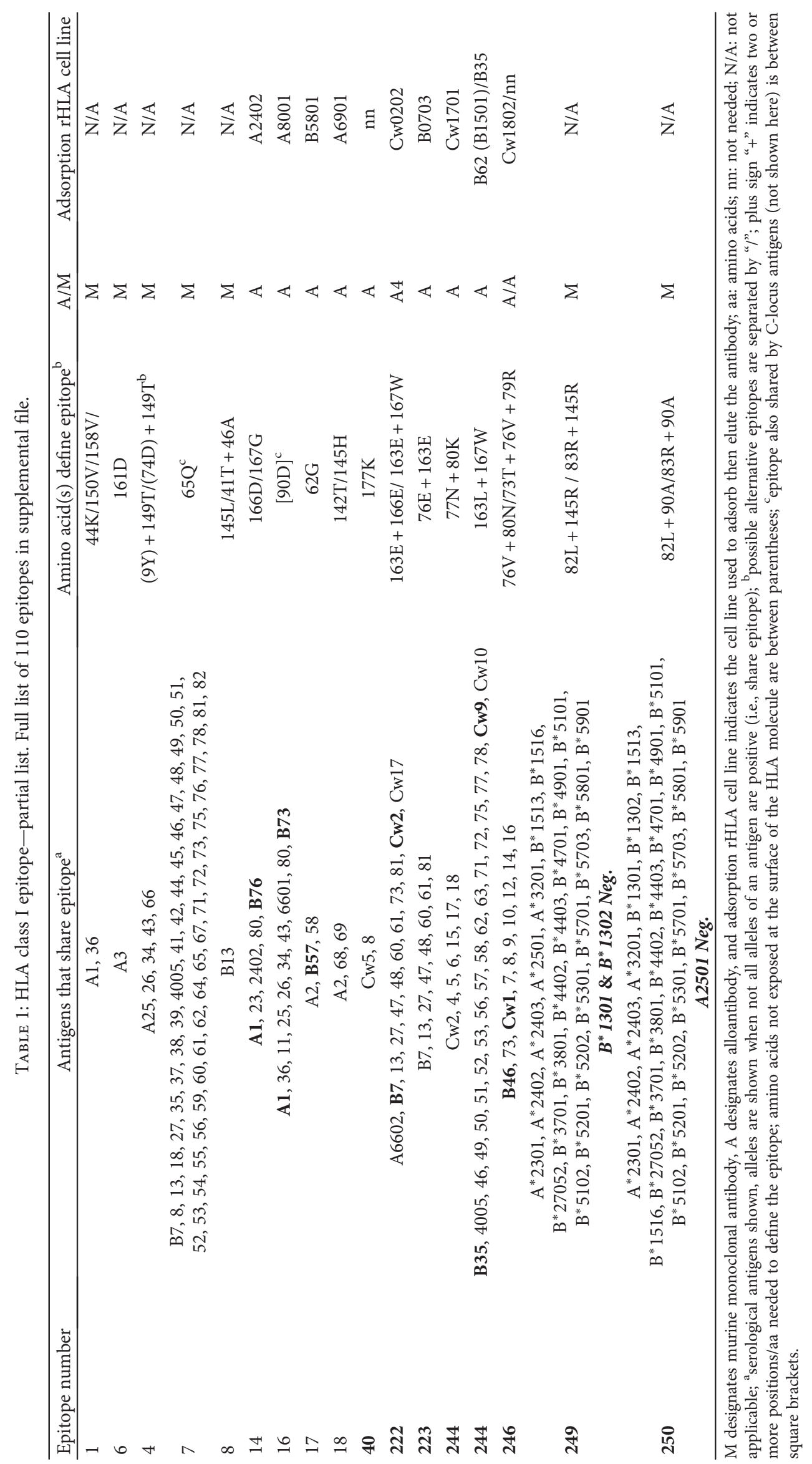




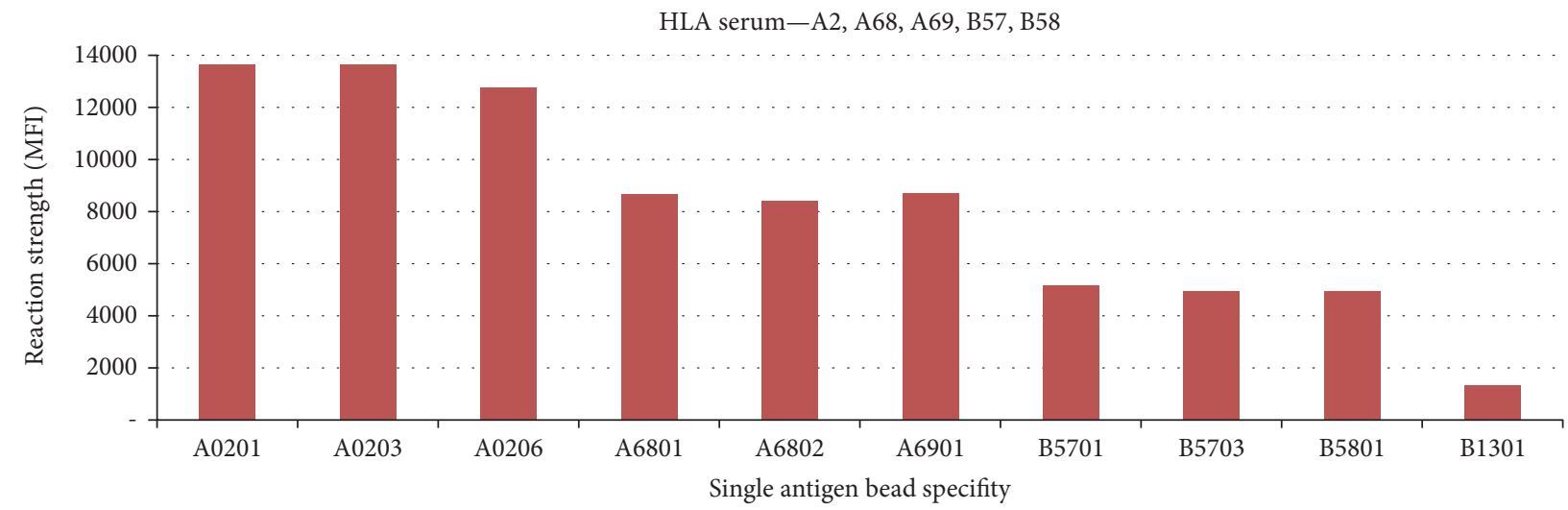

(a)

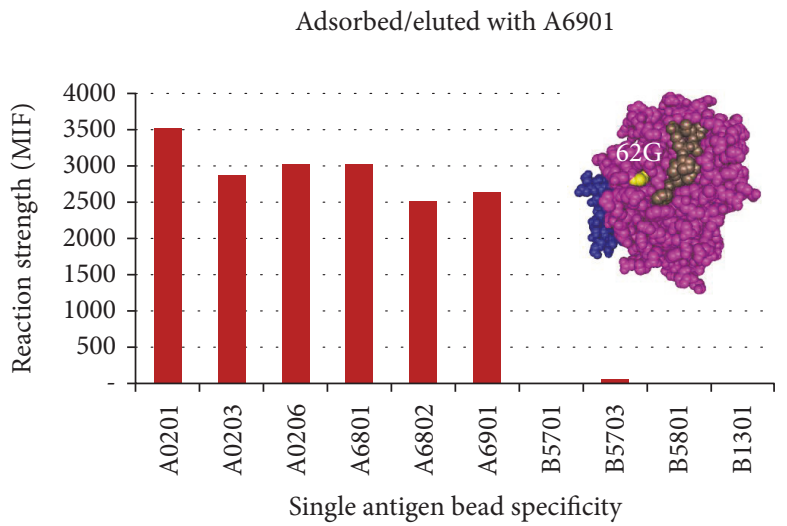

(b)

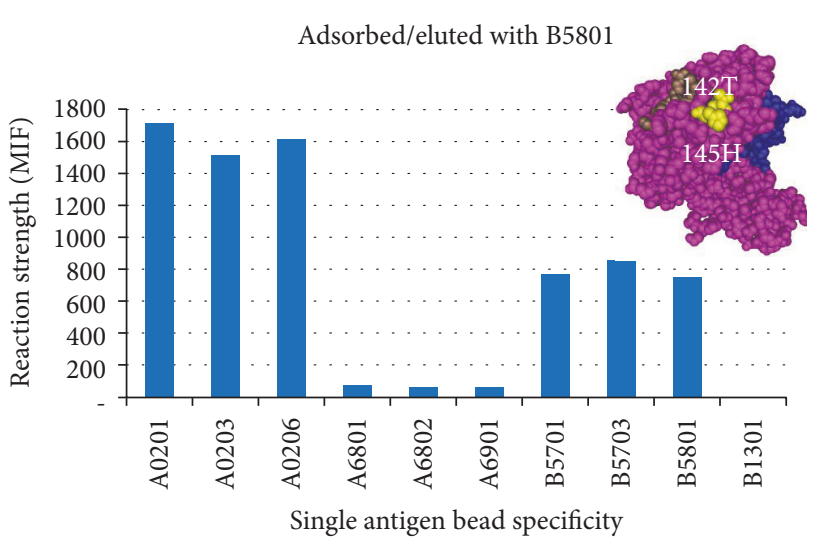

(c)

Figure 4: Alloserum with specificity A2, A68, A69, B57, and B58 (a). Antibody eluted from adsorption with A6901 recombinant cells has the specificity of A2, A68, and A69 (b). Antibody eluted from adsorption with B5801 recombinant cells has the specificity of A2, B57, and 58 (c).

TABLE 2: Epitopes on intact antigens targeted by naturally occurring antibodies-partial list. Complete list in supplemental file.

\begin{tabular}{|c|c|c|c|c|c|}
\hline Epitope number & $\begin{array}{c}\text { Dissociated } \\
\text { antigen(s) }\end{array}$ & Epitope site & Epitope number & Dissociated antigen(s) & Epitope site \\
\hline 5059 & A0101 & $158 V+163 R$ & 5073 & B76 & $163 \mathrm{~L}+166 \mathrm{D}$ \\
\hline 201 & A2 & $43 Q+62 G$ & 5075 & $\mathrm{Cw}^{*} 0102,0302,0303,0304,1402,1802$ & 219W \\
\hline 3 & $\mathrm{~A} 23, \mathrm{~A} 24$ & $65 \mathrm{G}$ & 5076 & Cw16 & $193 \mathrm{~L}$ \\
\hline 31 & A30, 31 & $56 \mathrm{R}$ & 5077 & Cw17 & $170 \mathrm{G}$ \\
\hline 5064 & A3002 & $17 S+76 \mathrm{E}$ & 5078 & Cw7 & $273 S$ \\
\hline 5066 & A6602 & $149 \mathrm{~T}$ & 5081 & Cw9, Cw10 & $163 \mathrm{~L}+173 \mathrm{~K}$ \\
\hline 5068 & A80 & $56 \mathrm{E}+$ & 5085 & B8 & $(67 F)+131 R$ \\
\hline 406 & B2705 & $\begin{array}{c}65 \mathrm{Q}+69 \mathrm{~A} \\
+80 \mathrm{~T}\end{array}$ & 5086 & Cw6 & $\begin{array}{c}80 \mathrm{~K}+90 \mathrm{D} \\
+(114 \mathrm{D})\end{array}$ \\
\hline 236 & B57, B58 & $43 \mathrm{P}+62 \mathrm{G}$ & & & \\
\hline
\end{tabular}

Plus sign "+" indicates two or more positions/aa needed to define the epitope; amino acids not exposed at the surface of the HLA molecule are between parentheses.

with a frequency of $f=0.0 \%$ to $6.1 \%$, we defined 19 epitopes. Class I epitopes were found to be shared by antigens of the same locus or by inter-locus antigens-BC or ABC. Epitopes are defined by 1, 2, 3, or 4 aa's. For example, 17 A-locus epitopes were defined by 1 aa, two B-locus epitopes by 4 aa's, or two $\mathrm{ABC}$ loci epitopes defined by 2 aa's. In addition, amino acids and positions on the HLA class I heavy chain epitopes were found at varying frequencies in epitope definitions.
The most frequent was position 163 located in the alpha 2 domain, and the aa threonine $(\mathrm{T})$ was found to be the most frequent in our studies.

The following examples illustrate HLA class I epitopes for the A-locus, B-locus, and C-locus and AB-, BC-, and ABCloci antigens. Illustration shows $\mathrm{SA}$ beads specificity, antigens sharing the epitopes, and their position on the HLA class I heavy chain. 
TABLe 3: Partial list of epitopes on HLA class I antigens. Complete list in supplemental file.

\begin{tabular}{|c|c|c|c|c|c|c|c|c|c|c|c|c|c|c|c|c|c|c|}
\hline Antigen & Number of epitopes & & & & & & & & Epit & spe nu & mber & & & & & & & \\
\hline $\mathrm{A} 1$ & 11 & 1 & 12 & 13 & 14 & 15 & 16 & 208 & 238 & 241 & 242 & 248 & & & & & & \\
\hline A2 & 16 & 2 & 13 & 17 & 18 & 19 & 27 & 32 & 38 & 201 & 210 & 211 & 238 & 242 & 247 & 412 & 422 & \\
\hline \multirow{2}{*}{ A25 } & \multirow{2}{*}{19} & 4 & 12 & 16 & 23 & 24 & 27 & 32 & 38 & 209 & 211 & 213 & 214 & 233 & 238 & 241 & 243 & \\
\hline & & 247 & 249 & 423 & & & & & & & & & & & & & & \\
\hline A80 & 9 & 13 & 14 & 15 & 16 & 28 & 29 & 208 & 241 & 242 & A 80 & 9 & 13 & 14 & 15 & 16 & 28 & 29 \\
\hline B13 & 16 & 7 & 8 & 21 & 22 & 24 & 32 & 33 & 43 & 217 & 218 & 222 & 223 & 233 & 235 & 250 & 418 & \\
\hline B54 & 17 & 7 & 25 & 32 & 33 & 204 & 215 & 216 & 224 & 226 & 228 & 229 & 232 & 233 & 234 & 401 & 402 & 410 \\
\hline B76 & 13 & 7 & 14 & 22 & 25 & 33 & 43 & 211 & 216 & 218 & 227 & 233 & 240 & 403 & B76 & 13 & 7 & 14 \\
\hline Cw1 & 5 & 32 & 205 & 232 & 246 & 421 & & & & & & & & & & & & \\
\hline CW2 & 5 & 32 & 39 & 205 & 222 & 244 & & & & & & & & & & & & \\
\hline CW4 & 4 & 32 & 205 & 232 & 244 & & & & & & & & & & & & & \\
\hline CW9 & 6 & 32 & 39 & 205 & 245 & 246 & 421 & & & & & & & & & & & \\
\hline CW10 & 6 & 32 & 39 & 205 & 245 & 246 & 421 & & & & & & & & & & & \\
\hline
\end{tabular}

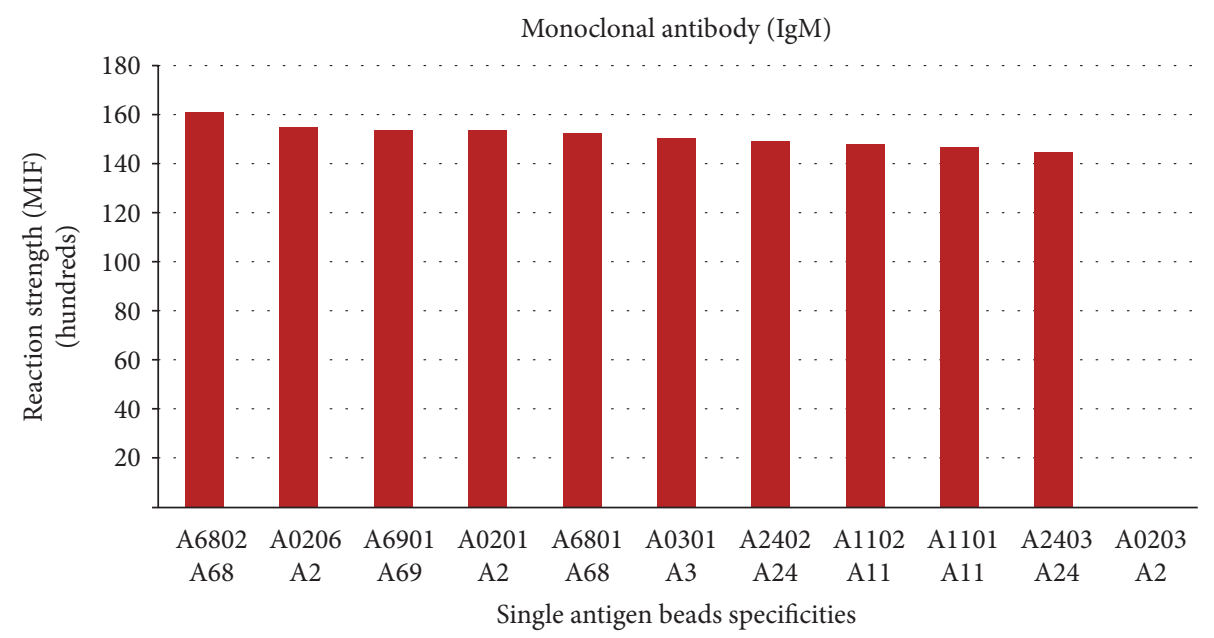

\begin{tabular}{llccc}
\hline & & \multicolumn{3}{c}{ aa position } \\
Antigen & Allele & 149 & 150 & 151 \\
A1 & A*0101 & A & V & H \\
\hline A68 & A*6802 & A & A & H \\
A2 & A*0206 & A & A & H \\
A69 & A*6901 & A & A & H \\
A2 & A*0201 & A & A & H \\
A68 & A*6801 & A & A & H \\
A3 & A*0301 & A & A & H \\
\hline
\end{tabular}

\begin{tabular}{llccc}
\hline & & \multicolumn{3}{c}{ aa position } \\
Antigen & Allele & 149 & 150 & 151 \\
A1 & A*0101 & A & V & H \\
\hline A24 & A*2402 & A & A & H \\
A11 & A*1102 & A & A & H \\
A11 & A*1101 & A & A & H \\
A24 & A*2403 & A & A & H \\
A2 & A*0203 & T & A & H \\
& & & & \\
\hline
\end{tabular}

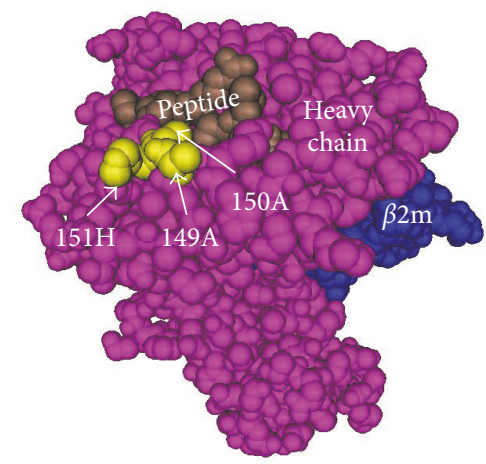

Figure 5: Epitope 422 shared by A-locus antigens A2, A3, A11, A24, A68, and A69 defined by the aa acid combination 149A + 150A + 151H. One amino acid substitution at position 149 (aa T substituted for aa a) could be the reason that A2 allele A*0203 is negative while alleles HLA $\mathrm{A}^{*} 0201$ and $\mathrm{A}^{*} 0206$ are positive.

A-locus: Epitope 422 is shared by A-locus antigens A2, A3, A11, A24, A68, and A69 defined by 149A +150A $+151 \mathrm{H}$ combined. Three amino acids at three positions are necessary to define this epitope; indeed, HLA-A*02:01 and $\mathrm{A}^{*} 02: 06$ are positive while $\mathrm{A}^{*} 02: 03$ is negative. $A^{*} 02: 01$ and $A^{*} 02: 06$ share epitope 422 defined as $149 \mathrm{~A}+150 \mathrm{~A}+151 \mathrm{H}$, while negative antigen $\mathrm{A}^{*} 02: 03$ does not share the epitope. $\mathrm{A}^{*} 02: 03$ has $150 \mathrm{~A}+151 \mathrm{H}$ but has 


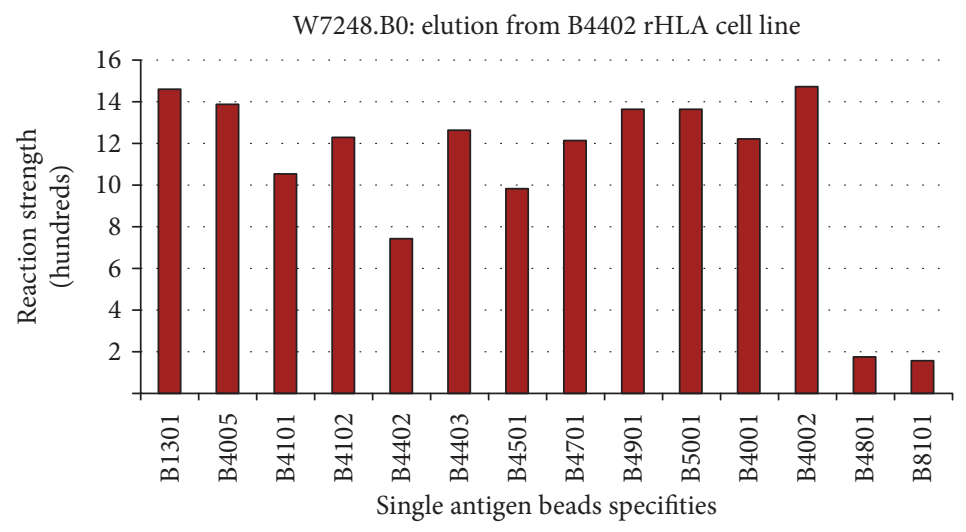

\begin{tabular}{lcc}
\hline Antigen & $\begin{array}{c}\text { Allele } \\
\text { B0702 }\end{array}$ & $\begin{array}{c}\text { aa \& } \\
\text { position } \\
\text { 41 A }\end{array}$ \\
\hline B13 & B1301 & T \\
B4005 & B4005 & T \\
B41 & B4101 & T \\
B41 & B4102 & T \\
B44 & B4402 & T \\
B44 & B4403 & T \\
B45 & B4501 & T \\
B47 & B4701 & T \\
B49 & B4901 & T \\
B50 & B5001 & T \\
B60 & B4001 & T \\
B61 & B4002 & T \\
B48 & B4801 & A \\
B81 & B8101 & A \\
\hline & &
\end{tabular}

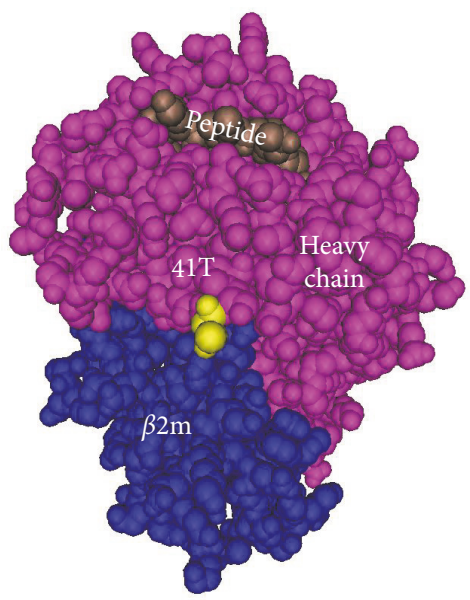

Figure 6: Epitope 21 shared by the B-locus antigens B13, B4005, B41, B44, B45, B47, B49, B50, B60, and B61 and defined by 41 T.
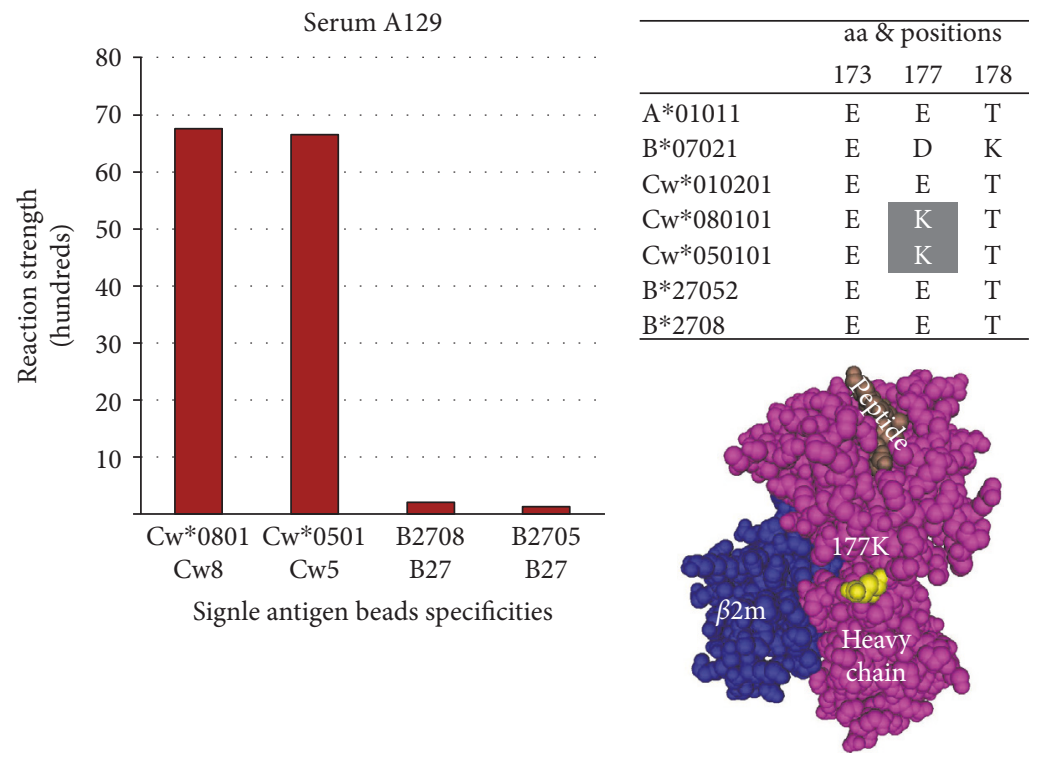

Figure 7: Epitope 40 shared by the C-locus antigens $\mathrm{Cw}^{*} 0801$ and $\mathrm{Cw}^{*} 0501$ and defined by $177 \mathrm{~K}$.

threonine $(\mathrm{T})$ at position 149 instead of alanine (A) - one amino acid difference in the epitope renders the antibody to be nonreactive with $A^{*} 02: 03$. The aa defining epitope 422 are exposed at the surface of the heavy chain and are within the binding span of the HLA antibody. The furthest amino acids are $7.88 \AA$ apart (Figure 5).

B-locus: Epitope 21 is shared by B-locus antigens B13, B4005, B41, B44, B45, B47, B49, B50, B60 (B4001), and B61 

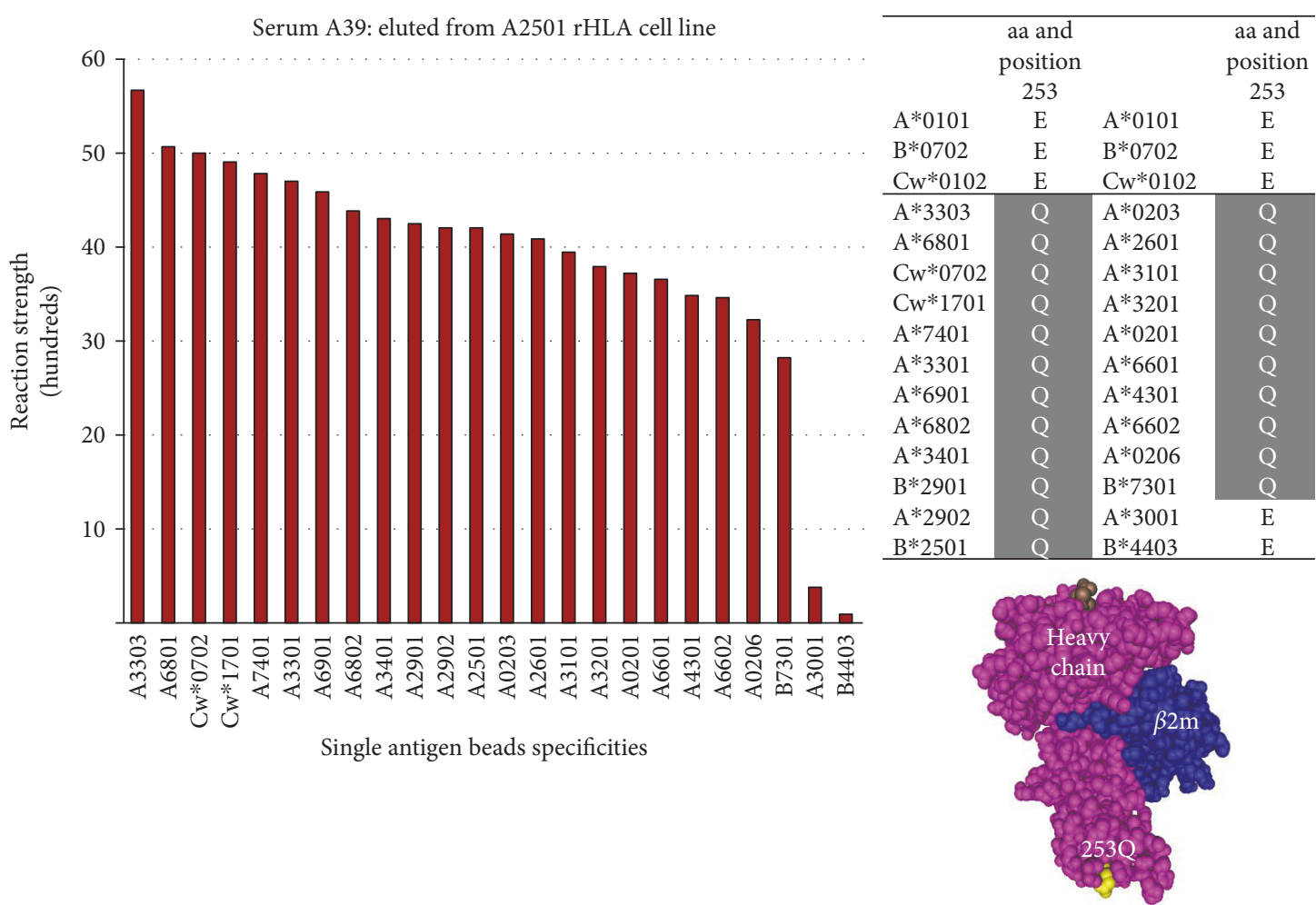

Figure 8: Epitope 38 shared by the ABC-loci antigens A2, A25, A26, A29, A31, A32, A33, A34, A43, A66, A68, A69, A74, B73, Cw7, and Cw17 and defined by the amino acid glutamine (Q) at position 253 .

Table 4: Cryptic (C) epitopes on dissociated class I HLA antigen-partial list. Complete list in supplemental file.

\begin{tabular}{|c|c|c|c|c|c|}
\hline Epitope number & Dissociated antigen(s) & Epitope site & Epitope number & Dissociated antigen(s) & Epitope site $^{\mathrm{c}}$ \\
\hline 5006 & A3002 & $(152 \mathrm{R})$ & 5033 & Cw2 & $(211 \mathrm{~T})$ \\
\hline 5007 & A31, A33 & $(73 \mathrm{I})$ & 5036 & Cw17 & $(116 \mathrm{~F})+(143 \mathrm{~S})$ \\
\hline 5008 & A3401 & $(63 N)+(66 \mathrm{~K})$ & 5038 & Cw6 & $(9 \mathrm{D})+(97 \mathrm{~W})$ \\
\hline 5009 & A3402 & $(63 N)+(66 \mathrm{~K})+(156 \mathrm{~L})$ & 5039 & Cw7 & $(66 \mathrm{~K})+(99 S)$ \\
\hline 5010 & A80 & $(31 S)$ & 5049 & A6602 & $(114 Q)+163 E$ \\
\hline 5027 & B8 & (9D) & 5052 & B76 & $(70 N)+166 \mathrm{D}$ \\
\hline 5031 & B82 & $(24 S)+(99 F)$ & & & \\
\hline
\end{tabular}

${ }^{c}$ Amino acids and their positions on the HLA-dissociated antigens define each epitope. In intact antigens, these amino acids are not exposed at the surface (cryptic).

(B4002) and defined by 41T. Threonine (T) is exclusively unique to the antigens at position 41 located in the alpha 1 domain of the HLA class I heavy chain (Figure 6).

C-locus: Epitope 40 shared by the C-locus antigens $\mathrm{Cw}^{*} 0801$ and $\mathrm{Cw}^{*} 0501$ and defined by $177 \mathrm{~K}$ located in the alpha 2 domain of the HLA heavy chain (Figure 7).

AB-Loci: Epitope 205 shared by the AB-loci A32, A74, $\mathrm{B} 7, \mathrm{~B} 8, \mathrm{~B} 4005, \mathrm{~B} 41, \mathrm{~B} 42, \mathrm{~B} 48, \mathrm{~B} 60, \mathrm{~B} 61, \mathrm{~B} 73$, and B81 and defined by $109 \mathrm{~L}+131 \mathrm{R}$ - the two positions are $11.8 \AA$ apart and therefore within the binding span of the antibody. Also, the C-locus antigens Cw1, Cw2, Cw4, Cw5, Cw6, Cw7, Cw8, Cw9, Cw10, Cw12, Cw14, Cw15, Cw16, Cw17, and Cw18 share the same amino acids at positions 109 and131 but were not tested with the C-locus beads at the time of the study.
Epitope 24 is shared by the $\mathrm{AB}$-loci Bw4-associated antigens A23, A24, A25, A32, B13, B2705, B37, B38, B44, B47, B49, B51, B52, B53, B57, B58, B59, B63, and B77 and defined by either $82 \mathrm{~L}$ or $83 \mathrm{R}$ located in the alpha 1 domain of the HLA class I heavy chain.

Epitope 423 is shared by the AB-loci Bw4-associated antigens A23, A25, A32, B2705, B37, B38, B44, B47, B49, B51, B52, B53, B57, B58, B59, B63, and B77 (A24, B13 negative) and defined by $83 R+144 Q+145 R$. This epitope was defined using a monoclonal antibody and seems to be a variant of epitope 24 shared by all Bw4-associated antigens. Other variants of the BW4-associated antigens epitope (epitopes 249 and 250) also defined with monoclonal antibodies (Table 1).

BC-Loci: Epitope 246 is shared by BC-loci antigens B46, B73, Cw1, Cw7, Cw8, Cw9, Cw10, Cw12, Cw14, and Cw16 


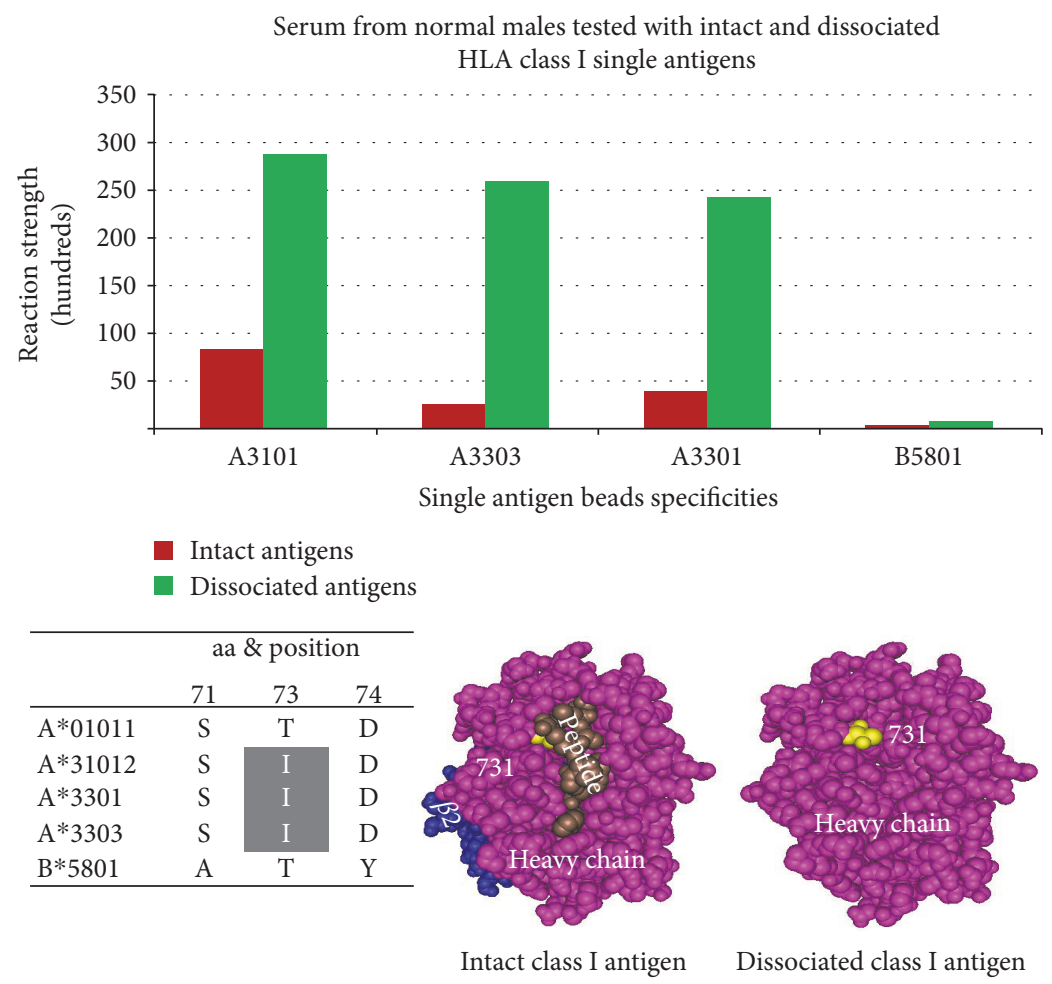

FIgURE 9: Epitope 5007 shared by the HLA class I A-locus antigens A31 and A33 and defined by isolucine (I) at position 73. The epitope is accessible on the dissociated antigens and show stronger reactivity when the peptide has been dissociated from the heavy chain. Position 73 is not exposed in an intact HLA class I antigen. After acid buffer treatment and neutralization of the eluate, epitope 5007 becomes exposed and reacts with the antibody 10 -fold.

TABLE 5: MICA epitopes.

\begin{tabular}{|c|c|c|c|}
\hline Epitope number & MICA antigens sharing epitope & aa/position define epitope ${ }^{\mathrm{a}}$ & rMICA cells used for adsorption/elution \\
\hline 6001 & MICA* $001,012,018$ & $(24 \mathrm{~T})$ & $\mathrm{MICA}^{*} 018$ \\
\hline 6002 & $\mathrm{MICA}^{*} 001,002,004,007,009,012,018,027$ & $91 \mathrm{Q}$ & ND \\
\hline 6003 & 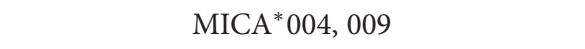 & $122 \mathrm{~V}$ & ND \\
\hline 6004 & 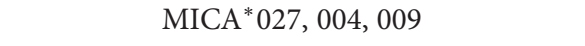 & $(36 \mathrm{Y}) / 129 \mathrm{~V} / 173 \mathrm{E}$ & MICA*004 \\
\hline 6005 & MICA*017 & $91 \mathrm{R}$ & ND \\
\hline 6006 & $\mathrm{MICA}^{*} 004$ & $181 \mathrm{R}$ & $\mathrm{ND}$ \\
\hline 6007 & $\mathrm{MICA}^{*} 027$ & $213 \mathrm{I} / 251 \mathrm{R}$ & ND \\
\hline
\end{tabular}

ND: not done; amino acids not exposed on the surface of the MICA antigen are shown between parentheses; ${ }^{\text {a }}$ possible alternative epitope definitions are separated by "l"; epitopes.

and defined by $76 \mathrm{~V}+80 \mathrm{~N}$. The two amino acids are $8.69 \AA$ apart which is within the binding span of the HLA antibody.

ABC-loci: Epitope 38 is shared by the ABC-loci antigens A2, A25, A26, A29, A31, A32, A33, A34, A43, A66, A68, A69, A74, B73, Cw7, and Cw17 and defined by the amino acid glutamine (Q) at position 253 of the HLA class I heavy chain located in the alpha 3 domain proximal to the cell membrane (Figure 8).

\subsection{Cryptic Epitopes on Dissociated HLA Class I Antigens.} Naturally occurring anti HLA antibodies were detected in nonalloimmunized healthy males [26], and 96 of their target epitopes were defined [16]. 58 natural antibodies are only reactive with dissociated HLA class I antigens, heavy chain only (Table 4). 56 unique epitopes on dissociated HLA class I defined [16].

Epitope 5007 is shared by the HLA class I A-locus antigens A31 and A33 and defined by isoleucine (I) at the cryptic position 73. Antibody reactivity with the intact antigen is obstructed because position 73 is located under the peptide. It is slightly reactive with the intact HLA class I antigens. Reactivity increased by up to 10 -fold with the dissociated antigens (heavy chain only)-when $\beta 2 \mathrm{~m}$ and the peptide are dissociated from the heavy chain (Figure 9).

Epitope 5024 is shared by the HLA class I B-locus antigens B7, B42, B54, B55, B56, B67, B81, and B82 and defined by $66 \mathrm{I}+70 \mathrm{Q}$. Reactions strength of the antibody is stronger 


\begin{tabular}{lc} 
MICA \\
\hline Antigen & $\begin{array}{c}\text { aa position } \\
91\end{array}$ \\
\hline MICA*001 & Q \\
MICA*002 & Q \\
MICA*004 & Q \\
MICA*007 & Q \\
MICA*009 & Q \\
MICA*012 & Q \\
MICA*018 & Q \\
MICA*027 & Q \\
MICA*017 & R \\
\hline
\end{tabular}

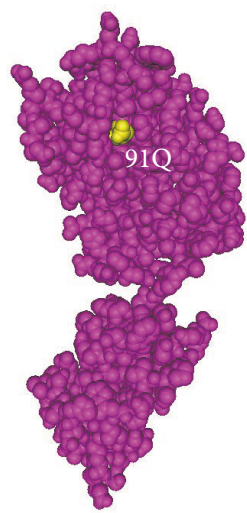

FIgURe 10: Epitope 6002 shared by MICA antigens MICA*001, 002, 004, 007, 009, 012, 018, and 027 and defined by glutamine $(\mathrm{Q})$ at position 91 .

TABle 6: Partial list of HLA class II DR epitopes defined based on aa acid sequence of the beta chain of the antigens. Complete list in supplemental file.

\begin{tabular}{lcc}
\hline $\begin{array}{l}\text { Epitope } \\
\text { number }\end{array}$ & DR antigens sharing epitope & $\begin{array}{c}\text { Position/ } \\
\text { amino acid }\end{array}$ \\
\hline 1001 & DR7, DR9, DR53 & $4 \mathrm{Q}$ \\
1004 & DR4, DR10 & $11 \mathrm{~V}$ \\
1008 & DR7 & $25 \mathrm{Q}$ \\
1017 & DR11 & $58 \mathrm{E}$ \\
1018 & DR7, DR8, DR11, DR12, DR13, & $70 \mathrm{D}$ \\
& DR16, DR51, DR103 \\
1028 & DR1, DR4, DR7, DR9, DR10, \\
1029 & DR11, DR12, DR13, DR14, DR15, \\
1039 & DR1, DR7, DR9, DR15, DR16, & $77 \mathrm{~T}$ \\
& DR51, DR52, DR53, DR103 \\
1032 & DR7, DR8, DR9, DR10, DR11, DR12, & 78V \\
& DR13, DR14, DR17, DR18, DR52 & 140A \\
\hline
\end{tabular}

with the unobstructed epitope after dissociation of the peptide from the heavy chain.

Epitope 5037 is shared by the HLA C-locus antigens Cw4, Cw6, Cw17, and Cw18 and defined by $73 \mathrm{~A}+77 \mathrm{~N}$. Antibody reaction strength increases with the unobstructed epitope after removal of the peptide.

3.3. MICA Epitopes. MICA or MHC class I polypeptiderelated sequence $\mathrm{A}$ antigens have similar aa structure as the HLA class I ABC heavy chains. However, MICA antigens are not associated with a peptide and beta 2 microglobulin. Seven epitopes were defined for MICA antigens (Table 5).

Epitope 6002 is shared by MICA antigens MICA*001, 002, 004, 007, 009, 012, 018, and 027 and defined by glutamine (Q) at position 91; therefore, 91Q defines the epitope (Figure 10).

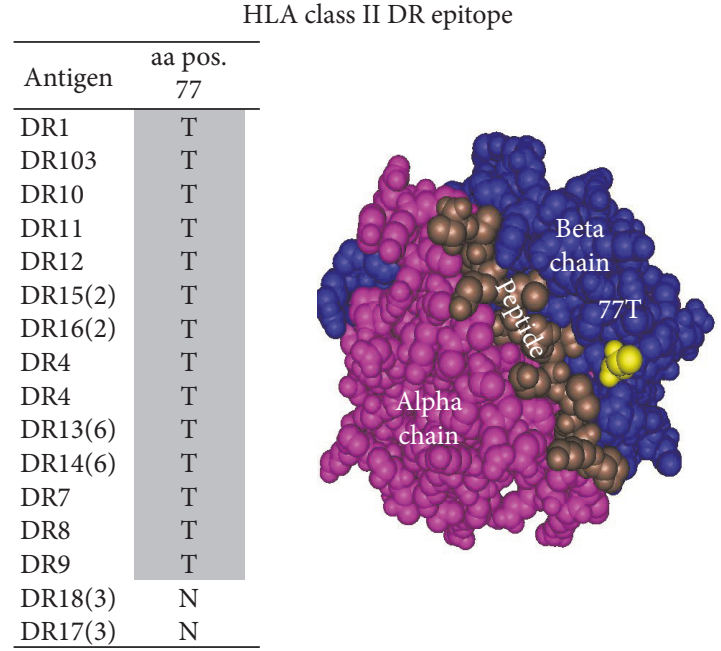

FIgURe 11: Epitope 1028 shared by class II DR antigens DR1, DR4, DR7, DR9, DR10, DR11, DR12, DR13, DR14, DR15, DR16, DR51, DR53, and DR103 and defined by threonine (T) at position 77 .

Epitope 6004 is shared by MICA antigens MICA* 04,009 , and 027 and defined by (36Y), 129V, or 173E.

\subsection{Class II Epitopes}

3.4.1. HLA-DRB1 Epitopes. Unlike class I epitopes, the 60 HLA class II B1 epitopes were defined based solely on amino acid sequence of the DR antigen beta chain where all epitopes can be defined by one single amino acid at one position (Table 6). The number of epitopes for each DR antigen was from 8 to 21 epitopes.

For example, epitope 1028 is shared by class II DR antigens DR1, DR4, DR7, DR9, DR10, DR11, DR12, DR13, DR14, DR15, DR16, DR51, DR53, and DR103 and defined by threonine $(\mathrm{T})$ at position 77 (Figure 11).

3.4.2. HLA-DQA1 and HLA-DQB1 Epitopes. Eighteen HLA class II DQB1 and DQA1 epitopes are defined using the adsorption and elution assays described in the Materials and Methods above. Fifteen of the epitopes are located on the beta chain of the DQ antigen and three on the alpha chain (Table 7). The number of epitopes for DQB chains was 4-8 and only one for DQA chains (Table 8).

Sera from allosensitized patients can be expected to have anti-HLA antibodies to class I and II antigens. As illustrated in (Figure 12), this serum has antibodies directed against DR, $D Q$, and DP antigens. The serum was adsorbed with DQA1 ${ }^{*} 02: 01 / \mathrm{DQB} 1^{*} 04: 01$ rHLA cells and the eluted antibody reacted with DQ4, DQ5, and DQ6 antigens which share epitope 2007 (Table 7).

One antigen mismatch can elicit an immune response to several epitopes on an HLA antigen. A serum from renal transplant patient with $\mathrm{DQA1}{ }^{*} 02: 01 / \mathrm{DQB1}{ }^{*} 02: 02$ mismatch has two antibodies. One antibody targets epitope 2017 (defined by histidine $(\mathrm{H})$ in position 52) on the DQA1*02 : 01 alpha chain and the other antibody targets 
TABLe 7: Fifteen HLA class II DQ $\beta$ epitopes and three DQ $\alpha$ epitopes defined.

\begin{tabular}{|c|c|c|}
\hline Epitope number ${ }^{\mathrm{a}}$ & DQ antigens sharing epitope & Position/amino acid $^{\mathrm{b}}$ \\
\hline 2001 & DQB2 & $28 \mathrm{~S} / 30 \mathrm{~S} / 37 \mathrm{I} / 52 \mathrm{~L} / 55 \mathrm{~L}$ \\
\hline 2002 & DQB4 & $56 \mathrm{~L}$ \\
\hline 2003 & DQB4, DQB5, DQB6, DQB7, DQB8, DQB9 & $28 \mathrm{~T} / 46 \mathrm{~V} / 52 \mathrm{P}$ \\
\hline 2004 & DQB5, DQB6 & $84 \mathrm{E} / 85 \mathrm{~V} / 86 \mathrm{~A} / 89 \mathrm{G} / 90 \mathrm{I} / 221 \mathrm{Q}$ \\
\hline 2005 & DQB7 & $45 \mathrm{E}$ \\
\hline 2006 & DQB7, DQB8, DQB9 & $55 \mathrm{P}$ \\
\hline 2007 & DQB4, DQB5, DQB6 & $52 \mathrm{P}+55 \mathrm{R}$ \\
\hline 2008 & DQB2, DQB5, DQB7, DQB8, DQB9 & $(9 \mathrm{Y}+11 \mathrm{~F})$ \\
\hline 2009 & DQB2, DQB4, DQB5, DQB6, DQB8, DQB9 & $34 \mathrm{R}+45 \mathrm{G}$ \\
\hline 2010 & DQB4, DQB5, DQB6, DQB8, DQB9 & $45 \mathrm{G}+46 \mathrm{~V}$ \\
\hline 2011 & DQB5, DQB0601 & $38 \mathrm{~V}+46 \mathrm{~V}$ \\
\hline 2012 & DQB8, DQB9 & $45 \mathrm{G}+55 \mathrm{P}$ \\
\hline 2013 & DQB2, DQB4, DQB7, DQB8, DQB9 & $84 \mathrm{Q} / 85 \mathrm{~L} / 86 \mathrm{E} / 87 \mathrm{~L} / 89 \mathrm{~T} / 220 \mathrm{H} / 221 \mathrm{H}$ \\
\hline 2014 & DQB4, DQB7, DQB8, DQB9 & $77 \mathrm{~T}+84 \mathrm{Q} / 77 \mathrm{~T}+85 \mathrm{~L} / 77 \mathrm{~T}+86 \mathrm{E} / 77 \mathrm{~T}+87 \mathrm{~L} / 182 \mathrm{~N}$ \\
\hline 2015 & DQB5 & $70 \mathrm{G}+71 \mathrm{~A} / 116 \mathrm{I} / 125 \mathrm{~S}$ \\
\hline 2017 & DQA1*0201 & $47 \mathrm{~K} / 52 \mathrm{H} / 54 \mathrm{~L}$ \\
\hline 2018 & DQA1*04/DQA1*05/DQA1 ${ }^{*} 06$ & 40G/47C \\
\hline 2019 & DQA $1^{*} 03$ & $26 \mathrm{~S} / 47 \mathrm{Q} / 56 \mathrm{R} / 187 \mathrm{~T}$ \\
\hline
\end{tabular}

${ }^{a}$ Epitope 2008 defined using $\mathrm{mAb} ;{ }^{\mathrm{b}}$ possible alternative epitopes are separated by " "”; epitopes that are defined by more than a single position/aa are separated by "+"; amino acids not exposed at the surface of the HLA molecule are between parentheses.

TABLE 8: Number and epitopes on HLA class II DQA1 and DQB1 antigens.

\begin{tabular}{|c|c|c|c|c|c|c|c|c|c|}
\hline \multirow{2}{*}{$\frac{\text { Antigen }}{\text { DQA1 }^{*} 0201}$} & \multirow{2}{*}{$\frac{\text { Number of epitopes }}{1}$} & \multicolumn{8}{|c|}{ Epitopes } \\
\hline & & 2017 & & & & & & & \\
\hline DQA $1 * 03$ & 1 & 2019 & & & & & & & \\
\hline $\mathrm{DQA}^{*} 04$ & 1 & 2018 & & & & & & & \\
\hline DQ2 & 4 & 2001 & 2008 & 2009 & 2013 & & & & \\
\hline DQ4 & 7 & 2002 & 2003 & 2007 & 2009 & 2010 & 2013 & 2014 & \\
\hline DQ5 & 8 & 2003 & 2004 & 2007 & 2008 & 2009 & 2010 & 2011 & 2015 \\
\hline DQ0601 & 6 & 2003 & 2004 & 2007 & 2009 & 2010 & 2011 & & \\
\hline DQ7 & 6 & 2003 & 2005 & 2006 & 2008 & 2013 & 2014 & & \\
\hline DQ8 & 8 & 2003 & 2006 & 2008 & 2009 & 2010 & 2012 & 2013 & 2014 \\
\hline DQ9 & 8 & 2003 & 2006 & 2008 & 2009 & 2010 & 2012 & 2013 & 2014 \\
\hline
\end{tabular}

epitope 2001 (defined by leucine (L) in position 52) on the $\mathrm{DQB1}^{*} 02$ : 02 beta chain (Table 7). As shown in the table, alternative epitope definitions are separated by “/."

The efficacy of adsorption and elution assays is demonstrated where one serum with DQ specificity, including DQA $1^{*} 02$ : 01 , underwent four separate adsorptions and elutions with rHLA DQ cells. Two of the cells have the relevant DQA1*02 : 01 chain, and the eluted antibodies show positive reactions with all heterodimers that contain the DQA ${ }^{*} 02$ : 01chain (red and green bars). However, eluents from adsorptions with irrelevant cells (no DQA1*02 : 01 chain) showed negative reactions (yellow and blue bars) (Figure 13).

The following examples illustrate HLA-DQA1 and HLADQB1 epitopes. Illustration shows SA beads specificity, antigens sharing the epitopes and their position on the DQA1 and DQB1 chains.

HLA-DQA1 epitopes: epitope 2018 is shared by the alpha chains of the DQ4, DQ5, and DQ6 antigens and defined by glutamine $(\mathrm{Q})$ at position 53 .

HLA-DQB1 epitopes: epitope 2002 is shared exclusively by the beta chains of the DQ4 antigen and defined by leucine (L) in position 56 .

Epitope 2010 is shared by the beta chains of DQ antigens DQ4, DQ5, DQ6, DQ8, and DQ9 and defined by $45 \mathrm{G}+46 \mathrm{~V}$.

Epitope 2022 is exclusive to $\mathrm{DQB1}{ }^{*} 05$ : 01 chain on the DQ5 antigen and defined by $125 \mathrm{~S}+126 \mathrm{Q}$.

Epitope 2006 is shared by $\mathrm{DQB1}^{*} 03: 01$ (DQ7), DQB1*03:02 (DQ8), and DQB1*03:03 (DQ9) and 


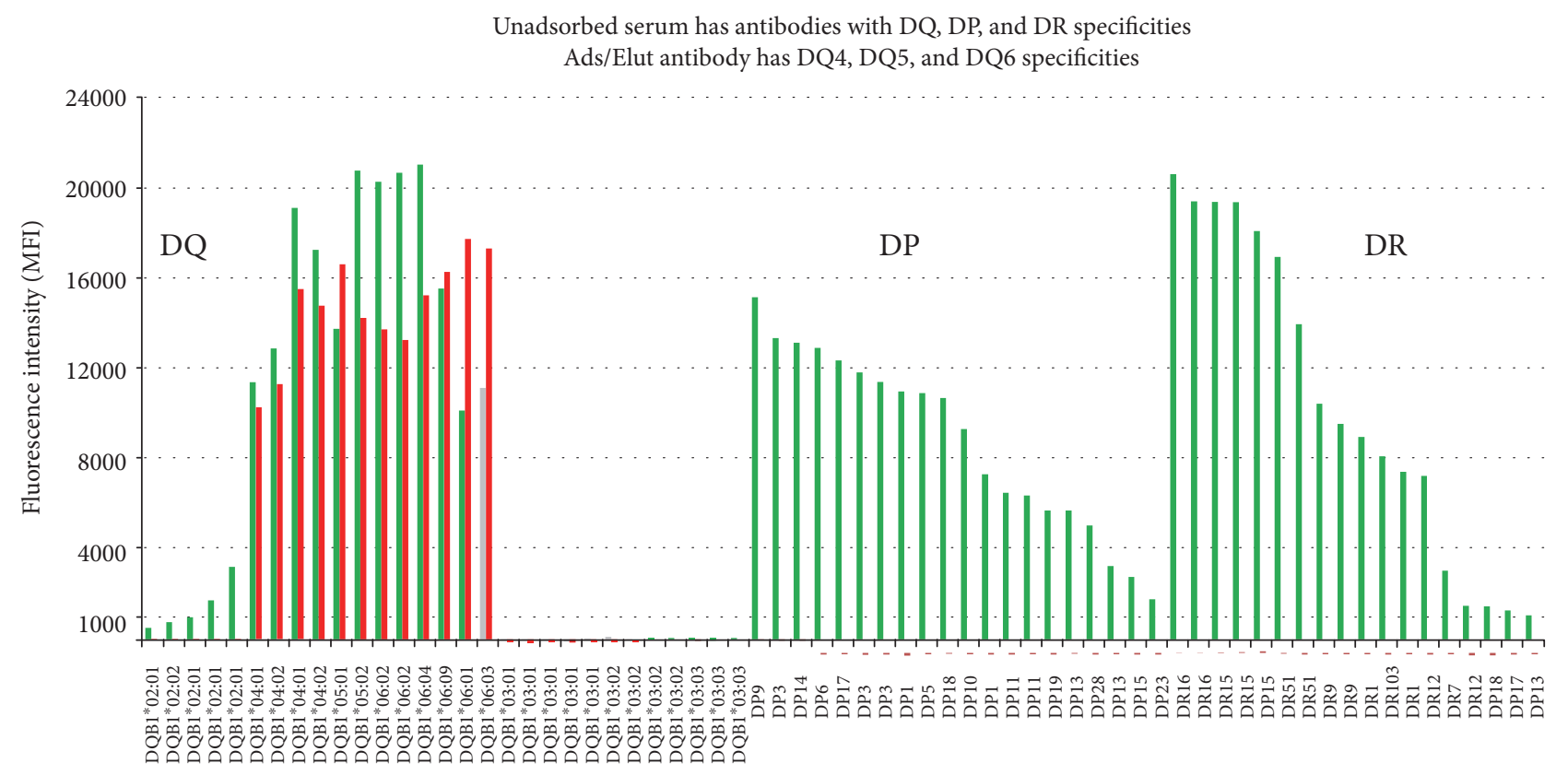

HLA DQ single antigen beads specificities

Unadsorbed serum

Adsorbed/eluted DQA1*02:01/DQB1*04:01 cells

\begin{tabular}{|c|c|c|c|c|c|}
\hline \multirow[t]{2}{*}{ HLA DQ allele } & \multicolumn{3}{|c|}{ Position/amino } & \multicolumn{2}{|c|}{$\begin{array}{c}\text { Position/amino } \\
\text { acid }\end{array}$} \\
\hline & 52 & 55 & & 52 & 55 \\
\hline DQB1*05:01 & $\mathrm{P}$ & $\mathrm{R}$ & DQB1*05:01 & $\mathrm{P}$ & $\mathrm{R}$ \\
\hline DQB1*04:01 & $\mathrm{P}$ & $\mathrm{R}$ & DQB1*06:04 & $\mathrm{P}$ & $\mathrm{R}$ \\
\hline DQB1*04:02 & $\mathrm{P}$ & $\mathrm{R}$ & DQB1*06:09 & $\mathrm{P}$ & $\mathrm{R}$ \\
\hline DQB1*05:01 & $\mathrm{P}$ & $\mathrm{R}$ & DQB1*02:01 & $\mathrm{L}$ & $\mathrm{L}$ \\
\hline DQB1*05:02 & $\mathrm{P}$ & $\mathrm{R}$ & DQB1*02:02 & $\mathrm{L}$ & $\mathrm{L}$ \\
\hline DQB1*06:01 & $\mathrm{P}$ & $\mathrm{R}$ & DQB1*03:01 & $\mathrm{P}$ & $\mathrm{P}$ \\
\hline DQB1*06:02 & $\mathrm{P}$ & $\mathrm{R}$ & DQB1*03:02 & $\mathrm{P}$ & $\mathrm{P}$ \\
\hline DQB1*06:03 & $\mathrm{P}$ & $\mathrm{R}$ & DQB1*03:03 & $\mathrm{P}$ & $\mathrm{P}$ \\
\hline
\end{tabular}

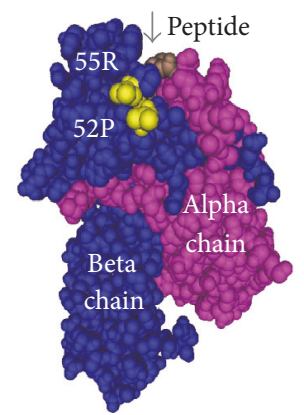

FIGURE 12: Unabsorbed serum has antibodies with specificity to DR, DQ, and DP antigens (green bars). After adsorbing the serum with rHLA DQ cells, the eluted antibody shows specificity to DQ antigens only (red bars).

defined by proline $(\mathrm{P})$ at position 55 on the beta chains of the DQ antigens.

3.4.3. HLA-DPB1 Epitopes. Five HLA class II DPB epitopes were defined. Four of the epitopes required 3-4 amino acids for definition, and one was defined by a single amino acid/position (Table 9).

Epitope 4001 is shared by the HLA class II DPB1 chains of the DP antigens $\mathrm{DPB} 1^{*} 01: 01, \mathrm{DPB} 1^{*} 03: 01$, $\mathrm{DPB}^{*} 05$ : 01, DPB1 ${ }^{*} 09$ : 01, DPB1*10 : 01, DPB1*11:01, $\mathrm{DPB}^{*} 13: 01, \mathrm{DPB} 1^{*} 14: 01, \mathrm{DPB}^{*} 17: 01$, and $\mathrm{DPB} 1{ }^{*} 19$ : 01 and defined by $84 \mathrm{D}+85 \mathrm{E}+86 \mathrm{~A}+87 \mathrm{~V}$. All four amino acids needed to define the epitope. Negative antigens that did not share epitope 4001 are shown as gray bars (Figure 14).

HLA class II DP epitope 4003 is shared by DPB1 chains $\mathrm{DPB}^{*} 02$ : 01, DPB1*04 : 02, DPB1*10 : 01, and DPB1*18 : 01 (red bars) and defined by $84 \mathrm{D}+85 \mathrm{E}+86 \mathrm{~A}+87 \mathrm{~V}$. Negative antigens that did not share epitope 4003 are shown in gray bars (Figure 15).

\section{Discussion}

Cross-reactivity of antibodies with HLA antigens has been investigated for decades $[4,5,7-9,27]$. Studies to identify HLA epitope, the target of antibodies, started more than 50 years ago [10], and numerous other studies followed since then $[5,6,11,28-34]$. The amino acid structure of HLA antigen chains was reported for the HLA A2 in 1987 [12], and now, complete sequences of all known HLA antigen chains are readily available online [23]. Single antigens expressed on a mammalian cell line allowed us to simplify adsorption/elution assays and isolate one antibody from multispecific allosera, with multiple antibodies, and test the isolated antibody with the single antigen beads to more accurately determine antibody specificity. Isolated antibodies tested with large panels of HLA class I or class II single antigen beads were shown to be positive with certain antigens of the bead panels and negative with others. It is, therefore, reasonable to assume that the positive antigens share a public 


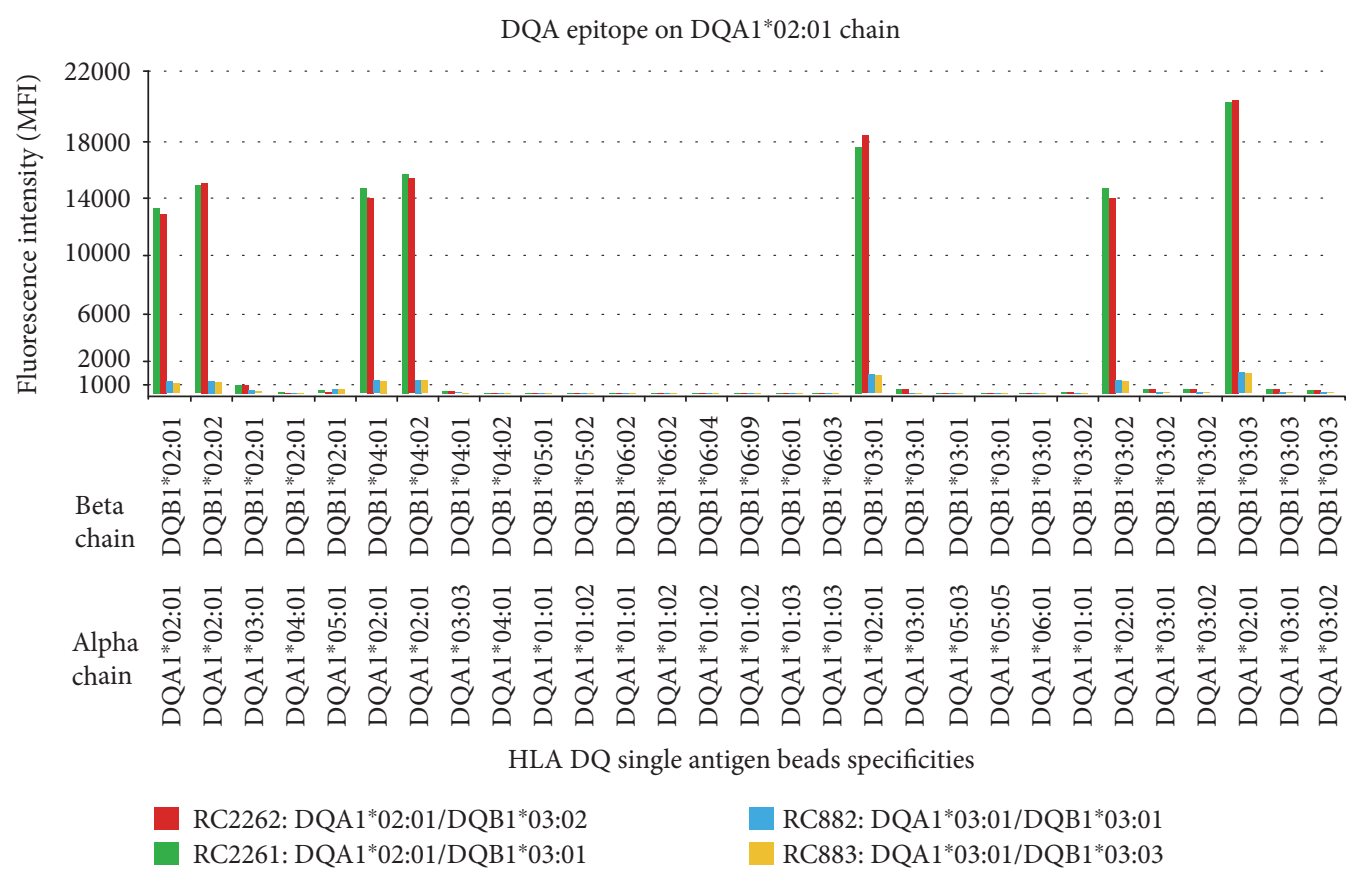

\begin{tabular}{|c|c|c|c|}
\hline HLA DQ allele & $\begin{array}{l}\text { Position/ } \\
\text { amino acid } \\
52\end{array}$ & HLA DQ allele & $\begin{array}{l}\text { Position/ } \\
\text { amino acid } \\
52\end{array}$ \\
\hline DQA1*01:01 & $\mathrm{S}$ & DQA1*01:01 & $S$ \\
\hline DQA $1 * 02: 01$ & $\mathrm{H}$ & DQA $1 * 03: 03$ & $\mathrm{R}$ \\
\hline DQA $1 * 01: 01$ & $\mathrm{~S}$ & DQA1*04:01 & $\mathrm{R}$ \\
\hline DQA $1{ }^{*} 01: 02$ & $\mathrm{~S}$ & DQA $1 * 05: 01$ & $\mathrm{R}$ \\
\hline DQA $1 * 01: 03$ & S & DQA1*05:03 & $\mathrm{R}$ \\
\hline DQA1*03:01 & $\mathrm{R}$ & DQA1*05:05 & $\mathrm{R}$ \\
\hline DQA1*03:02 & $\mathrm{R}$ & DQA $1 * 06: 01$ & $\mathrm{R}$ \\
\hline
\end{tabular}

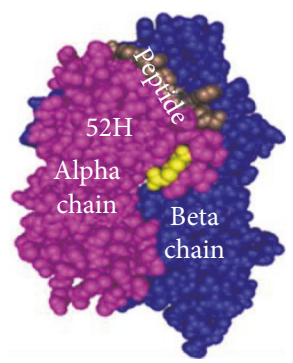

FIGURE 13: Several DQ antigens (heterodimers) with the DQA1*02: 01 chain are shown below. They all share epitope 2017 which is defined by histidine $(\mathrm{H})$ in position 52 of DQA1*02:01 chain. Eluted antibodies from relevant DQ antigens are positive (red and green bars). Eluted antibodies from irrelevant (no DQA ${ }^{*} 02: 01$ ) are negative (yellow and blue bars).

TABLE 9: HLA class II DP epitopes.

\begin{tabular}{|c|c|c|}
\hline Epitope number & DP antigens sharing epitope & Position/amino acid $^{\mathrm{a}}$ \\
\hline 4001 & $\begin{array}{l}\text { DPB1*0101, DPB1*0301, DPB1*0501, DPB1*0901, DPB1*1001, } \\
\text { DPB1 }^{*} 1101, \mathrm{DPB} 1 * 1301, \mathrm{DPB} 1{ }^{*} 1401, \mathrm{DPB} 1^{*} 1701, \mathrm{DPB} 1^{*} 1901\end{array}$ & $84 \mathrm{D}+85 \mathrm{E}+86 \mathrm{~A}+-87 \mathrm{~V}$ \\
\hline 4002 & DPB1*0301, DPB1*0901, DPB1*1401, DPB1*1701 & $55 \mathrm{D}+56 \mathrm{E}+-57 \mathrm{D}$ \\
\hline 4003 & $\mathrm{DPB}^{*} 0201, \mathrm{DPB} 1^{*} 0402, \mathrm{DPB} 1^{*} 1001, \mathrm{DPB} 1^{*} 1801$ & $55 \mathrm{D}+56 \mathrm{E}+-57 \mathrm{E}$ \\
\hline 4004 & $\mathrm{DPB}^{*} 1101, \mathrm{DPB} 1^{*} 1501$ & $(33 \mathrm{Q})$ \\
\hline 4005 & $\mathrm{DPB}^{*} 0201, \mathrm{DPB} 1^{*} 0401, \mathrm{DPB} 1^{*} 0402$ & $84 \mathrm{G}+85 \mathrm{G}+86 \mathrm{P}+87 \mathrm{M}$ \\
\hline
\end{tabular}

${ }^{a}$ Epitopes defined by more than a single position/aa are separated by "+"; amino acids not exposed at the surface of the HLA molecule are between parentheses.

epitope which can easily be confirmed by looking at the amino acid sequences of these antigens.

HLA single antigen bead assays are simplified assigning anti-HLA antibody specificities by simply listing all antigens that are positive with the serum or antibody. Because a positive antibody-antigen reaction indicates binding of antibody to the single antigen on the bead, we postulate that the antibody must be specific to the antigen. However, the single antigen beads assay often reveals more antibody specificities than other antibody detection assays. This is clearly seen when an immunological response to a mismatched antigen produces antibody specificity to nondonor antigens and in some cases unexpectedly to rare antigens. HLA antigens share public epitopes; therefore, the extra antibody specificity 


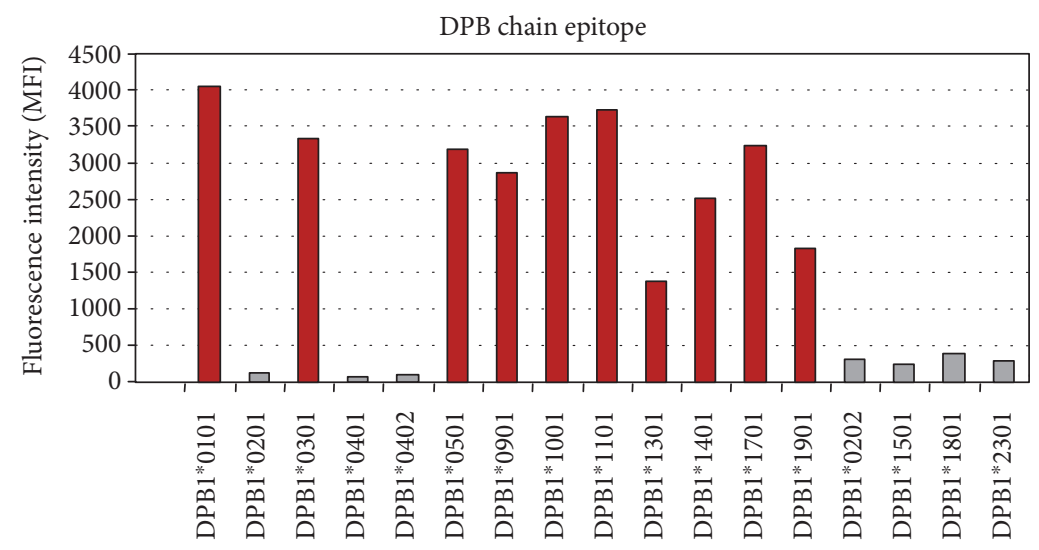

Specificities of DP single antigen beads

\begin{tabular}{|c|c|c|c|c|}
\hline \multirow{2}{*}{ Allele } & \multicolumn{4}{|c|}{ Amino acids and position } \\
\hline & 84 & 85 & 86 & 87 \\
\hline DPB1*01:01 & $\mathrm{D}$ & E & A & V \\
\hline DPB1*01:01 & $\mathrm{D}$ & $\mathrm{E}$ & A & V \\
\hline DPB1*03:01 & $\mathrm{D}$ & $\mathrm{E}$ & A & V \\
\hline DPB1*05:01 & D & E & A & V \\
\hline DPB1*09:01 & D & E & A & V \\
\hline DPB1*10:01 & D & E & A & V \\
\hline DPB1*11:01 & D & $\mathrm{E}$ & A & V \\
\hline DPB1*13:01 & $\mathrm{D}$ & $\mathrm{E}$ & A & V \\
\hline DPB1*14:01 & $\mathrm{D}$ & E & A & V \\
\hline DPB1*17:01 & D & $\mathrm{E}$ & A & V \\
\hline DPB1*19:01 & D & E & A & V \\
\hline $\mathrm{DPB} 1 * 02: 01$ & $\mathrm{G}$ & $\mathrm{G}$ & $\mathrm{P}$ & $\mathrm{M}$ \\
\hline DPB1*04:01 & G & G & $\mathrm{P}$ & M \\
\hline DPB1*04:02 & G & G & $\mathrm{P}$ & M \\
\hline
\end{tabular}

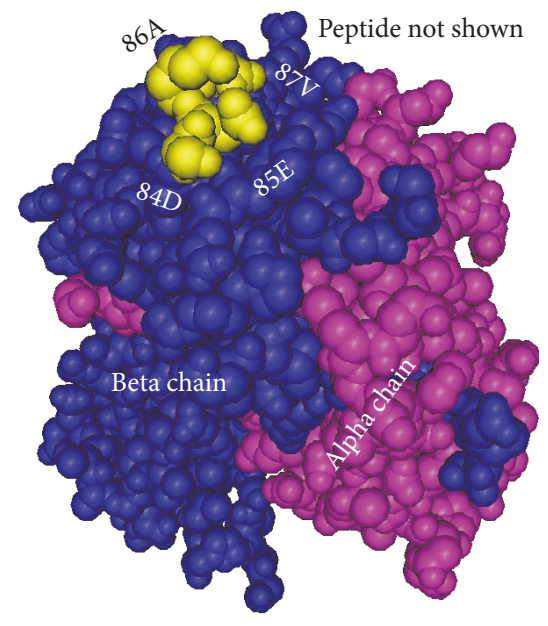

Figure 14: HLA class II DP epitope 4001 shared by DPB chains DPB1*0101, DPB1*0301, DPB1*0501, DPB1*0901, DPB1*1001, DPB1*1101, DPB1*1301, DPB1*1401, DPB1*1701, and DPB1*1901 (red bars) and defined by $84 \mathrm{D}+85 \mathrm{E}+86 \mathrm{~A}+87 \mathrm{~V}$. Negative antigens that did not share epitope 4001 are shown in (gray bars).

of non-donor-specific and rare antigens can now be explained as antibody binding to public epitopes located on the positive antigens. Defining epitopes of HLA gives us better understanding of the breadth of non-donor-specific specificities found in sera. For example, specificity of antibodies to rare antigens like A80 and B76 were unexpectedly higher than the antigens' frequency $(<0.5 \%)$ in the general population. The two antigens have 9 and 13 epitopes, respectively (Table 3).

HLA epitopes were defined using computer software by searching, in published sequences of class I and class II antigens, for exclusive amino acids at the same position(s) that are shared by all positive-reacting antigens. Amino acid sequences and the $3 \mathrm{D}$ structures of available HLA antigens, used to ensure that aa's are exposed on the surface of the antigens, helped in defining close to 300 epitopes. Assay-positive antigens that share epitopes, defined by exclusively shared aa's, correspond to the antibody specificities. Although it is beyond the scope of assays used in our studies to determine the exact conformational arrangement of each epitope and all amino acids that constitute the epitope, the defining amino acids must be a focal part of the epitope. Public epitopes found exclusively on positive antigens and not on negative antigens are likely not coincidences. For several epitopes defined in our studies, the difference of one aa among alleles of the same antigen, at least one amino acid position can determine whether the allele is positive or negative with the antibody (Figure 5).

We have demonstrated that some antibodies target an epitope on one single antigen (private epitope) or an epitope on a group of two or more antigens (public epitopes). Furthermore, in anti-DQ antisera, immunological responses can produce antibodies to epitopes located on either or both polymorphic chains of the DQ antigens.

The usefulness of epitopes beyond determining correct antibody specificity in sera of transplant patients has been the subject of study recently. Reports on matching donors and recipients or selecting organ donors based on epitope matching are numerous. For example, Duquesnoy reported 


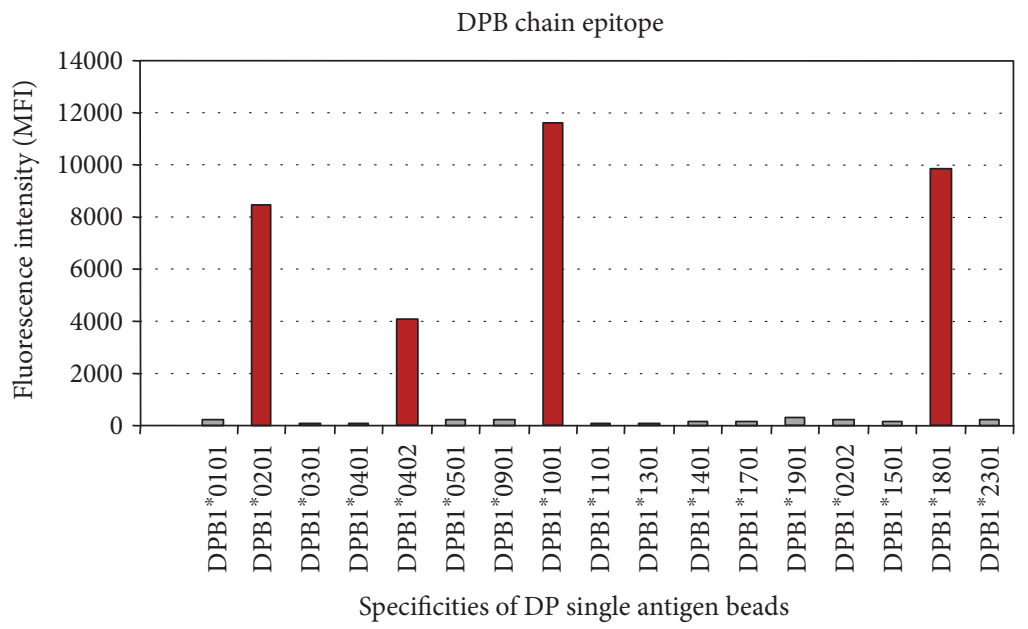

\begin{tabular}{|c|c|c|c|c|c|c|}
\hline \multirow{2}{*}{ Allele } & \multicolumn{6}{|c|}{ Amino acids and position } \\
\hline & 53 & 54 & 55 & 56 & 57 & 58 \\
\hline DPB1*01:01 & $\mathrm{R}$ & $\mathrm{P}$ & A & A & $\mathrm{E}$ & $\mathrm{Y}$ \\
\hline DPB1*02:01 & $\mathrm{R}$ & $\mathrm{P}$ & $\mathrm{D}$ & $\mathrm{E}$ & $\mathrm{E}$ & $\mathrm{Y}$ \\
\hline DPB1*04:02 & $\mathrm{R}$ & $\mathrm{P}$ & $\mathrm{D}$ & $\mathrm{E}$ & $\mathrm{E}$ & $\mathrm{Y}$ \\
\hline DPB1*10:01 & $\mathrm{R}$ & $\mathrm{P}$ & D & E & E & $\mathrm{Y}$ \\
\hline DPB1*18:01 & $\mathrm{R}$ & $\mathrm{P}$ & D & $\mathrm{E}$ & E & $\mathrm{Y}$ \\
\hline DPB1*01:01 & $\mathrm{R}$ & $\mathrm{P}$ & A & A & $\mathrm{P}$ & $\mathrm{Y}$ \\
\hline DPB1*03:01 & $\mathrm{R}$ & $\mathrm{P}$ & $\mathrm{D}$ & $\mathrm{E}$ & D & $\mathrm{Y}$ \\
\hline DPB1*04:01 & $\mathrm{R}$ & $\mathrm{P}$ & A & A & $\mathrm{E}$ & $\mathrm{Y}$ \\
\hline DPB1*05:01 & $\mathrm{R}$ & $\mathrm{P}$ & E & A & E & Y \\
\hline DPB1*09:01 & $\mathrm{R}$ & $\mathrm{P}$ & $\mathrm{D}$ & $\mathrm{E}$ & D & $\mathrm{Y}$ \\
\hline DPB1*11:01 & $\mathrm{R}$ & $\mathrm{P}$ & A & A & E & $\mathrm{Y}$ \\
\hline DPB1*13:01 & $\mathrm{R}$ & $\mathrm{P}$ & A & A & E & $\mathrm{Y}$ \\
\hline DPB1*14:01 & $\mathrm{R}$ & $\mathrm{P}$ & $\mathrm{D}$ & E & D & $\mathrm{Y}$ \\
\hline DPB1*17:01 & $\mathrm{R}$ & $\mathrm{P}$ & $\mathrm{D}$ & E & D & $\mathrm{Y}$ \\
\hline DPB1*19:01 & $\mathrm{R}$ & $\mathrm{P}$ & $\mathrm{E}$ & A & $\mathrm{E}$ & $\mathrm{Y}$ \\
\hline
\end{tabular}

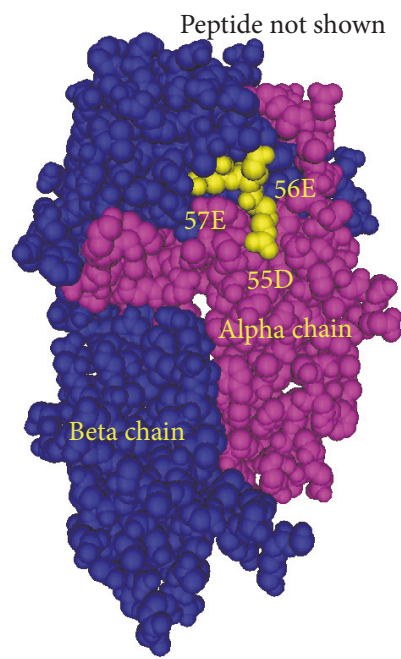

FIgURe 15: HLA class II DP epitope 4003 shared by DPB chains DPB1*0201, DPB1*0402, DPB1*1001, and DPB1*1801 (red bars) and defined by $84 \mathrm{D}+85 \mathrm{E}+86 \mathrm{~A}+87 \mathrm{~V}$. Negative antigens that did not share epitope 4003 are shown in (gray bars).

on HLA epitope-based matching for organ transplantation $[35,36]$. Wiebe reported on epitope matching to minimize de novo donor-specific antibodies to improve transplantation outcome [37] and Walton et al. reported on the usefulness of matching at the epitope level which protects against chronic lung allograft dysfunction [38].

\section{Conflicts of Interest}

Nadim El-Awar has no conflict of interest regarding the publication of this paper (retired from One Lambda Inc., or now Thermo Fisher Scientific, September 11, 2014). Vadim Jucaud has no conflict of interest regarding the publication of this paper. Anh Nguyen has no conflict of interest regarding the publication of this paper.

\section{References}

[1] P. I. Terasaki, "Humoral theory of transplantation," American Journal of Transplantation, vol. 3, no. 6, pp. 665-673, 2003.
[2] N. El-Awar, P. Terasaki, V. Lazda, A. Nikaein, C. Manning, and A. N. Arnold, "Almost all patients who are waiting for a regraft of a kidney transplant have anti-HLA antibodies," Transplantation Proceedings, vol. 34, no. 7, pp. 2531-2532, 2002.

[3] R. Pei, J. H. Lee, N. J. Shih, M. Chen, and P. I. Terasaki, "Single human leukocyte antigen flow cytometry beads for accurate identification of human leukocyte antigen antibody specificities," Transplantation, vol. 75 , no. 1, pp. 43-49, 2003.

[4] J. Colombani, M. Colombani, and J. Dusset, "Cross-reactions in the HLA-system with special reference to Da6 crossreacting group," in Histocompatibility Testing, P. I. Terasaki, Ed., pp. 79-92, Munksgaard, Los Angeles, 1970.

[5] A. A. Fuller, J. E. Trevithick, G. E. Rodey, P. Parham, and T. C. Fuller, "Topographic map of the HLA-A2 CREG epitopes using human alloantibody probes," Human Immunology, vol. 28, no. 3, pp. 284-305, 1990.

[6] Y. Konoeda, P. I. Terasaki, A. Wakisaka, M. S. Park, and M. R. Mickey, "Public determinants of HLA indicated by pregnancy antibodies," Transplantation, vol. 41, no. 2, pp. 253-259, 1986. 
[7] K. K. Mittal and P. I. Terasaki, "Cross-reactivity in the HL-A system,” Tissue Antigens, vol. 2, no. 2, pp. 94-104, 1972.

[8] G. E. Rodey, J. F. Neylan, J. D. Whelchel, K. W. Revels, and R. A. Bray, "Epitope specificity of HLA class I alloantibodies. I. Frequency analysis of antibodies to private versus public specificities in potential transplant recipients," Human Immunology, vol. 39, no. 4, pp. 272-280, 1994.

[9] A. Svejgaard and F. Kissmeyer-Nielsen, "Cross-reactive human HL-A isoantibodies," Nature, vol. 219, no. 5156, pp. 868-869, 1968.

[10] J. J. Van Rood and A. Van Leeuwen, "Leukocyte grouping. A method and its application," The Journal of Clinical Investigation, vol. 42, no. 9, pp. 1382-1390, 1963.

[11] R. J. Duquesnoy, "Structural epitope matching for HLAalloimmunized thrombocytopenic patients: a new strategy to provide more effective platelet transfusion support?" Transfusion, vol. 48, no. 2, pp. 221-227, 2008.

[12] P. J. Bjorkman, M. A. Saper, B. Samraoui, W. S. Bennett, J. L. Strominger, and D. C. Wiley, "Structure of the human class I histocompatibility antigen, HLA-A2," Nature, vol. 329, no. 6139, pp. 506-512, 1987.

[13] T. Akaza, N. El-Awar, A. Nguyen, J. Kitawaki, and T. Pl, "HLA class I epitopes: C-locus," Clinical Transplants, pp. 95-102, 2006.

[14] N. El-Awar, J. H. Lee, C. Tarsitani, and P. I. Terasaki, "HLA class I epitopes: recognition of binding sites by mAbs or eluted alloantibody confirmed with single recombinant antigens," Human Immunology, vol. 68, no. 3, pp. 170-180, 2007.

[15] N. El-Awar, P. I. Terasaki, J. Cai, C. T. Deng, M. Ozawa, and A. Nguyen, "Epitopes of the HLA-A, B, C, DR, DQ and MICA antigens," Clinical Transplants, pp. 175-194, 2007.

[16] N. El-Awar, P. I. Terasaki, A. Nguyen et al., "Epitopes of HLA antibodies found in sera of normal healthy males and cord blood," Clinical Transplants, pp. 199-214, 2008.

[17] N. El-Awar, P. I. Terasaki, A. Nguyen et al., "Epitopes of human leukocyte antigen class I antibodies found in sera of normal healthy males and cord blood," Human Immunology, vol. 70, no. 10, pp. 844-853, 2009.

[18] N. R. El-Awar, T. Akaza, P. I. Terasaki, and A. Nguyen, "Human leukocyte antigen class I epitopes: update to 103 total epitopes, including the C locus," Transplantation, vol. 84, no. 4, pp. 532-540, 2007.

[19] C. T. Deng, J. Cai, M. Ozawa, and N. El-Awar, "HLA class II DP epitopes," Clinical Transplants, pp. 195-202, 2007.

[20] C. T. Deng, J. Cai, C. Tarsitani, N. El-Awar, N. Lachmann, and M. Ozawa, "HLA class II DQ epitopes," Clinical Transplants, pp. 115-122, 2006.

[21] C. T. Deng, N. El-Awar, M. Ozawa, J. Cai, N. Lachmann, and P. I. Terasaki, "Human leukocyte antigen class II DQ alpha and beta epitopes identified from sera of kidney allograft recipients," Transplantation, vol. 86, no. 3, pp. 452-459, 2008.

[22] N. El-Awar, P. I. Terasaki, J. Cai et al., "Epitopes of HLA-A, B, C, DR, DQ, DP and MICA antigens," Clinical Transplants, pp. 295-321, 2009.

[23] Anthony Nolan Research Institute web site," May, 2003. http://www.anthonynolan.org.uk/HIG/data.html.

[24] A. G. Amit, R. A. Mariuzza, S. E. Phillips, and R. J. Poljak, "Three-dimensional structure of an antigen-antibody complex at 2.8 A resolution," Science, vol. 233, no. 4765, pp. 747-753, 1986.
[25] S. Sheriff, E. W. Silverton, E. A. Padlan et al., "Three-dimensional structure of an antibody-antigen complex," Proceedings of the National Academy of Sciences of the United States of America, vol. 84, no. 22, pp. 8075-8079, 1987.

[26] L. E. Morales-Buenrostro, P. I. Terasaki, L. A. Marino-Vázquez, J. H. Lee, N. El-Awar, and J. Alberú, ""Natural" human leukocyte antigen antibodies found in nonalloimmunized healthy males," Transplantation, vol. 86, no. 8, pp. 1111-1115, 2008.

[27] J. A. Lopez de Castro, J. A. Barbosa, M. S. Krangel, P. A. Biro, and J. L. Strominger, "Structural analysis of the functional sites of class I HLA antigens," Immunological Reviews, vol. 85, no. 1, pp. 149-168, 1985.

[28] R. J. Duquesnoy, "Human leukocyte antigen epitope antigenicity and immunogenicity," Current Opinion in Organ Transplantation, vol. 19, no. 4, pp. 428-435, 2014.

[29] A. A. Fuller, G. E. Rodey, P. Parham, and T. C. Fuller, "Epitope map of the HLA-B7 CREG using affinity-purified human alloantibody probes," Human Immunology, vol. 28, no. 3, pp. 306-325, 1990.

[30] L. K. Gaur, P. Antonelli, E. A. Clark, and J. A. Hansen, "Evolution of HLA class I epitopes defined by murine monoclonal antibodies: distribution in macaques," Human Immunology, vol. 17, no. 4, pp. 406-415, 1986.

[31] J. E. Gumperz, V. Litwin, J. H. Phillips, L. L. Lanier, and P. Parham, "The Bw4 public epitope of HLA-B molecules confers reactivity with natural killer cell clones that express NKB1, a putative HLA receptor," The Journal of Experimental Medicine, vol. 181, no. 3, pp. 1133-1144, 1995.

[32] P. Parham, "Antigenic determinants of the HLA-B7 molecule; Bw6- and B7-specific determinants are spatially separate," Immunogenetics, vol. 18, no. 1, pp. 1-16, 1983.

[33] R. D. Salter and P. Parham, "Mutually exclusive public epitopes of HLA-A,B,C molecules," Human Immunology, vol. 26, no. 2, pp. 85-89, 1989.

[34] A. M. Wan, P. Ennis, P. Parham, and N. Holmes, "The primary structure of HLA-A32 suggests a region involved in formation of the Bw4/Bw6 epitopes," Journal of Immunology, vol. 137, no. 11, pp. 3671-3674, 1986.

[35] R. J. Duquesnoy, "Epitope-based human leukocyte antigen matching for transplantation," Current Opinion in Organ Transplantation, vol. 19, no. 4, pp. 418-419, 2014.

[36] R. J. Duquesnoy, "HLA epitope based matching for transplantation," Transplant Immunology, vol. 31, no. 1, pp. 1-6, 2014.

[37] C. Wiebe, D. Pochinco, T. D. Blydt-Hansen et al., "Class II HLA epitope matching-a strategy to minimize de novo donor-specific antibody development and improve outcomes," American Journal of Transplantation, vol. 13, no. 12, pp. 31143122, 2013.

[38] D. C. Walton, S. J. Hiho, L. S. Cantwell et al., "HLA matching at the eplet level protects against chronic lung allograft dysfunction," American Journal of Transplantation, vol. 16, no. 9, pp. 2695-2703, 2016. 


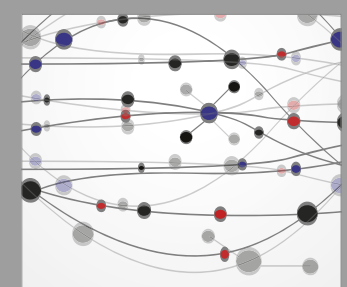

The Scientific World Journal
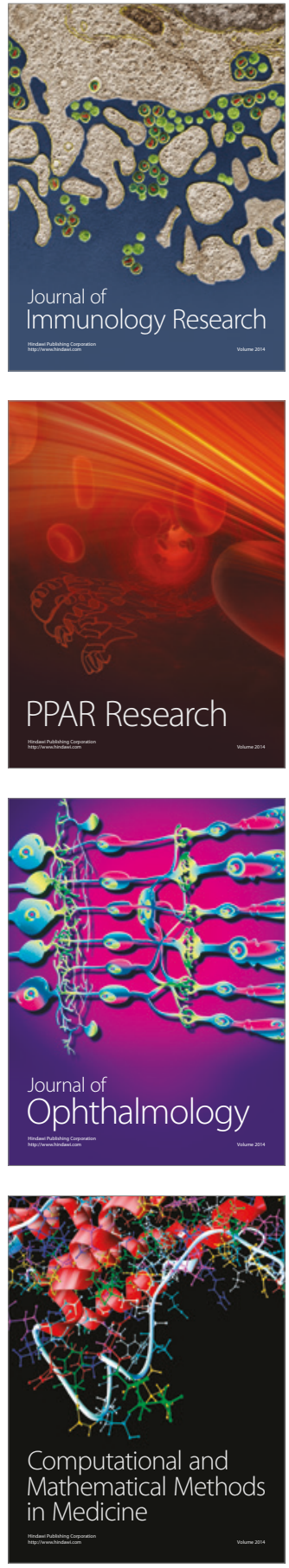

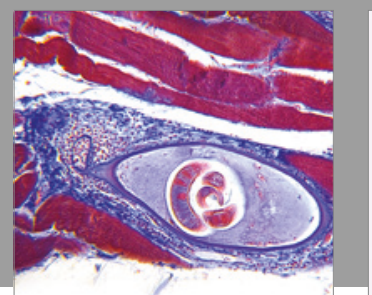

Gastroenterology Research and Practice
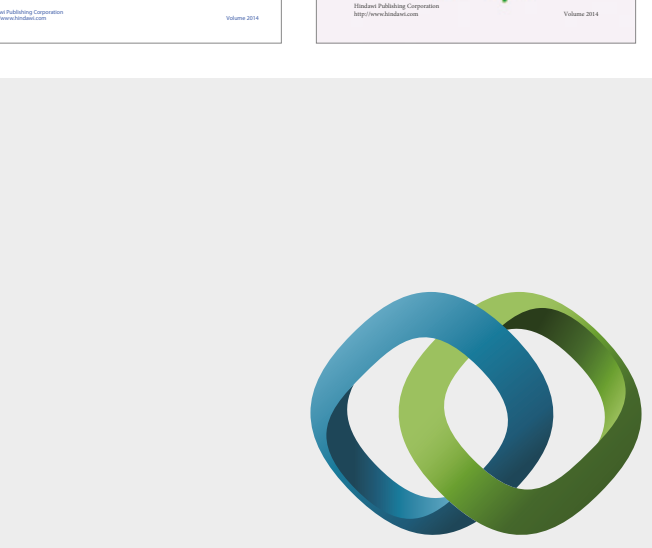

\section{Hindawi}

Submit your manuscripts at

https://www.hindawi.com
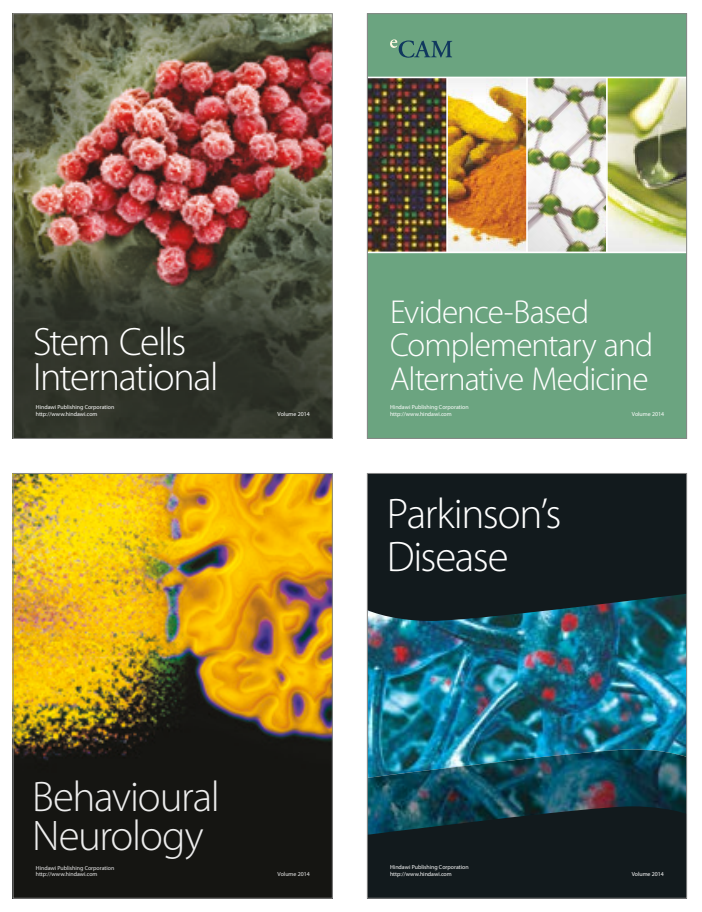
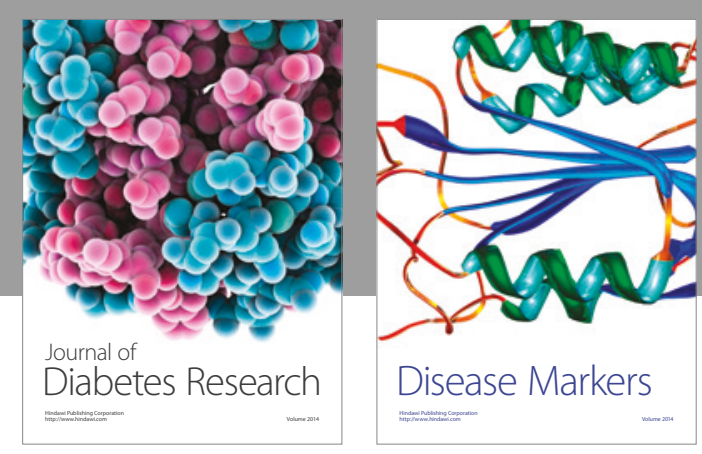

Disease Markers
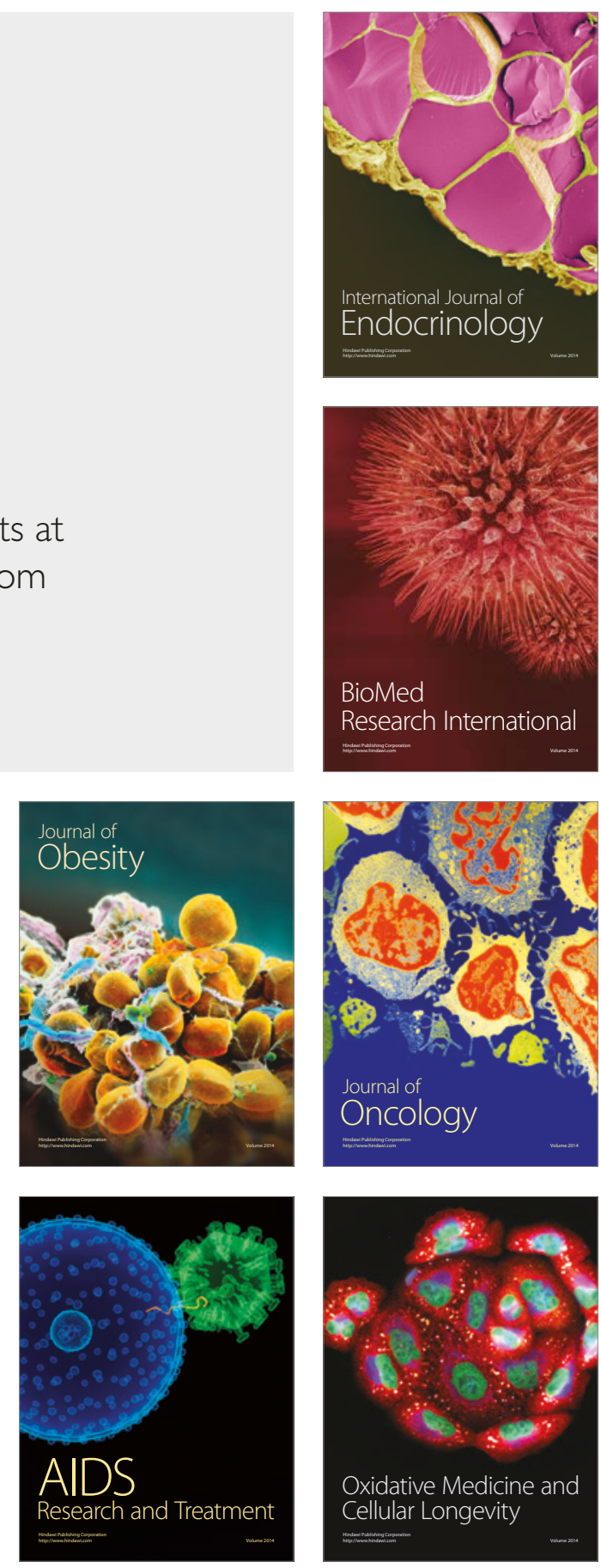